University of Rhode Island

DigitalCommons@URI

Open Access Master's Theses

1980

\title{
RADIOIMMUNOASSAY OF TESTOSTERONE AND ESTROGENS IN BLOODSTAINS FOR THE PURPOSE OF SEX IDENTIFICATION
}

Dennis Charles Hilliard

University of Rhode Island

Follow this and additional works at: https://digitalcommons.uri.edu/theses

\section{Recommended Citation}

Hilliard, Dennis Charles, "RADIOIMMUNOASSAY OF TESTOSTERONE AND ESTROGENS IN BLOODSTAINS FOR THE PURPOSE OF SEX IDENTIFICATION" (1980). Open Access Master's Theses. Paper 196.

https://digitalcommons.uri.edu/theses/196

This Thesis is brought to you for free and open access by DigitalCommons@URI. It has been accepted for inclusion in Open Access Master's Theses by an authorized administrator of DigitalCommons@URI. For more information, please contact digitalcommons-group@uri.edu. 


\author{
RADIOIMMUNOASSAY OF TESTOSTERONE AND ESTROGENS \\ IN BLOODSTAINS FOR THE PURPOSE OF \\ SEX IDENTIFICATION \\ BY \\ DENNIS CHARLES HILLIARD
}

A THESIS SUBMITTED IN PARTIAL FULFILLMENT OF THE REQUIREMENTS FOR THE DEGREE OF MASTER OF SCIENCE

IN

PHARMACOLOGY AND TOXICOLOGY

UNIVERSITY OF RHODE ISLAND

1980 
To whom it may concern.

Due to a lack in cataloging staff, many theses have not yet boen cataloged. Uncataloged theses do not circulate, thus limiting our interlibrary lou services. Until your thesis is cataloged, we would appreciate receiving your permission to copy the thesis if and when requested on Interlibrary Loan. The new copyrigit law requires the author's written permission for copying.

Please complete, sign, arid date the form below. Thank you. Yours truly,

SK: $\mathbf{v b}$

I hereby $\frac{d \mathrm{C}}{\text { do/do not }}$ grant permission to tine URI LAbrery to copy my tilesis for Interlibrary Ioan purposes until a circulating copy becumes available.

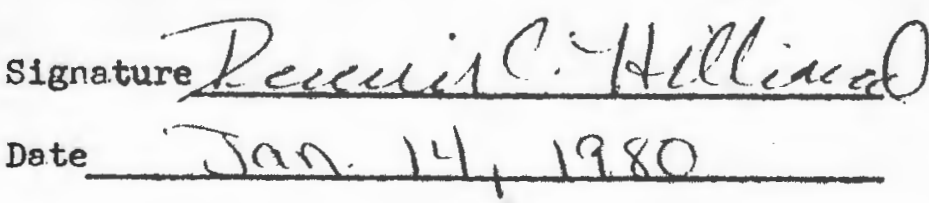

LO70-9 1978 rev. $6 / 79$ 
MASTER OF SCIENCE THESIS

$\mathrm{OF}$

DENNIS CHARLES HILLIARD

Approved:

Thesis Committee:

Chairman

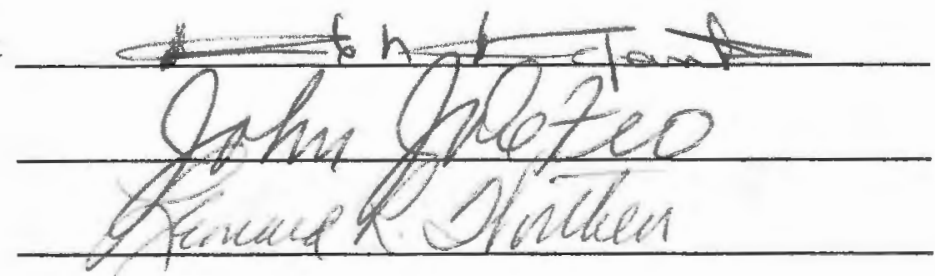

C.M. hichel

Dean of the Graduate School

UNIVERSITY OF RHODE ISLAND

1980 
SHORT TITLE

SEXUAL IDENTIFICATION FROM BLOODSTAINS 
ABSTRACT

The capabilities and the limitations involved in applying commercially prepared Radioimmunoassay (RIA) Kits, for testosterone (T) and estrogen (E), for the purpose of identifying the sexual origin of a bloodstain were examined. A total of forty whole blood samples were obtained from equal numbers of young healthy male and female volunteers. Bloodstains were prepared by absorbing these blood samples onto $2 \mathrm{x} 2 \mathrm{~cm}$ squares of white cotton linen. Two separate studies were conducted using these stains. Both studies examined the fractional recovery of $\mathrm{T}$ and $\mathrm{E}$ when extracted with diethyl ether, the ability of the RIA method to detect $T$ and $E$ present in the extract at three bloodstain ages (2, 30 , and 60 days after preparation) and whether a $T: E$ ratio could be utilized as a basis for discriminating between male and female bloodstain samples. The difference between the studies lies in the prior knowledge of the sex of each individual blood sample. In the first study the sex of each blood sample was known, (open study), whereas in the second study the individual sex was not known but the number of each sex was known (single-blind study). A cross-reactivity study was performed to determine the direct interference of several commonly used synthetic steroids with the RIAs. 
Significant amounts of $\mathrm{T}$ and $\mathrm{E}$ were detected in extracts of most bloodstains. Both the open and singleblind studies showed that there is a significant difference between male and female $T: E$ ratics and that this difference tends to diminish as the bloodstain age increases. The single blind study also showed this method to be at least 708 accurate when the bloodstain is 2 days old. Crossreactivity studies showed only one of the synthetic steroids tested reacted significantly with the estradiol antiserum. All other tests showed no significant cross-reactivity of the synthetic steroids tested with either the estradiol or testosterone antiseras. RIA of testosterone and estrogens in bloodstains is of practical value in determining the sexual origin of a bloodstain. 


\section{ACKNOWLEDGEMENTS}

The author first wishes to express his sincere appreciation to his major professor, Dr. David R. DeFanti, for his concern, assistance and patience throughout this investigation

The author wishes to thank those individuals who volunteered to participate in this study by donating a blood sample. Also, he wishes to express his appreciation to John Rivers, a medical technologist, for his participation in the initial part of this investigation.

The author wishes to sincerely thank the members of his committee, Dr. John J. DeFeo and Dr. Leonard R. Worthen, for their advice and encouragement.

The author wishes to jointly express his deep appreciation to his parents, Mr. and Mrs. Daniel M. Hilliard, and to his in-laws, Mr. and Mrs. Saverio Durso, for their encouragement and help.

The author especially wishes to express his gratefulness to his wife for her understanding and love throughout the investigation and for her incalculable aid in the preparation of this work. 
TABLE OF CONTENTS

PAGE

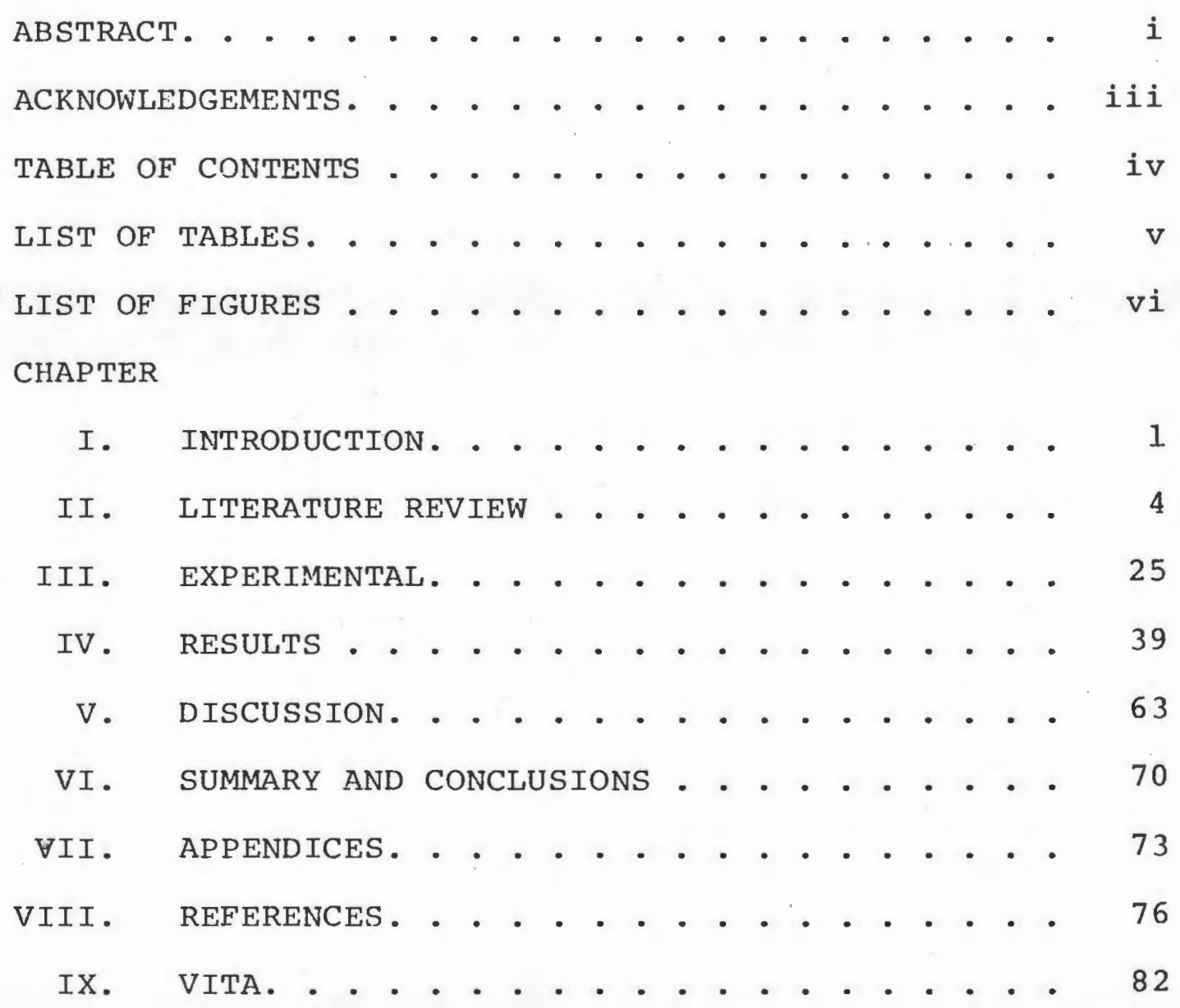




\section{LIST OF TABLES}

TABLE

PAGE

1. Solutions for RIA. . . . . . . . . . . 28

2. Antiserum Titer Determination. . . . . . . 29

3. Standard Solutions . . . . . . . . . 32

4. RIA Protocol . . . . . . . . . . . 35

5. Synthetic Steroid Standards for the Estradiol Cross-Reactivity Study ......... 37

6. Synthetic Steroid Standards for the Testosterone Cross-Reactivity Study . . . . . .

7. Average Fractional Recovery and Standard Errors ................... . 4 42

8. T:E Ratios for Open Study. . . . . . . . 54

9. T:E Ratios for Single-Blind study. . . . . 55

10. Mean T:E Ratio Values and Standard Errors. . 57

11. Cross-Reactivity of Steroids . . . . . . . 62

12. T-Test Analysis for Sex. . . . . . . . . 74

13. T-Test Analysis for Age. . . . . . . . . 74

14. Analysis of Variance Source Table for Open
Study Data. . . . . . . . . . . . . 75

15. Analysis of Variance Source Table for Single-
Blind study Data . . . . . . . . . . . 75 


\section{LIST OF FIGURES}

F IGURE

PAGE

1. Antibody-Antigen Interaction. . . . . . . . 12

2. Testosterone and Synthetic Progestins . . . . 22

2A. Estrogens and Synthetic Estrogens . . . . . 23

3. Antiserum Dilution Curves ......... . 40

4. Testosterone Standard Curve 2 Day Open Study. - 43

5. Estradiol Standard Curve 2 Day open Study . . . 44

6. Testosterone Standard Curve 30 Day Open Study - 45

7. Estradiol Standard Curve 30 Day Open Study. . . 46

8. Testosterone Standard Curve 60 Day Open Study and 2 Day Single-Blind Study. . . . . . . .

9. Estradiol Standard Curve 60 Day Open Study and 2 Day Single-Blind Study. . . . . . . . . 48

10. Testosterone Standard Curve 30 Day SingleBlind Study . . . . . . . . . . . . . . 49

11. Estradiol Standard Curve 30 Day Single-Blind Study................... . 50

12. Testosterone Standard Curve 60 Day SingleBlind Study . . . . . . . . . . . . 51

13. Estradiol Standard Curve 60 Day Single-Blind Study . . . . . . . . . . . . . 52

14. Testosterone Antiserum Cross-Reactivity Curves. 59

15. Estradiol Antiserum Cross-Reactivity Curves . . 60 


\section{INTRODUCTION}

Forensic serology involves the examination of physical evidence of a biological nature and includes the specialities of immunohemotology, biochemistry, enzymology and human genetics. Most physical evidence examined by a forensic serologist contains bloodstains of an unknown origin. Traditional approaches to the grouping of bloodstains involves a comparison of the genetic markers found in a stain with those of the suspect(s) and victim(s) involved in a crime.

Generally the information obtained from these genetic markers which is useful for forensic purposes deals with population frequency data. Each antigen or isoenzyme detected in a single bloodstain will decrease the possible number of people that might have left a particular stain. By using additional marker systems, the forensic scientist can reduce that probable percentage dramatically.

In some instances, such as those crimes in which there are no control bloodstains available for comparison, the blood grouping data alone are of little value to the investigators. It is occasionally possible, however, to obtain additional information from the stain concerning some physical characteristics of the individual who left the stain.

The possibilities of discerning the race, age and sex of the individual who left the stain are currently being 
investigated (Brown, 1977; Garner, 1979 and wigmore, 1979). It is the determination of the sexual origin of a bloodstain through the quantification of the sex hormones:

Testosterone ( $T$ ) and Estrogens (E) by radioimunoassay (RIA) techniques, that will be the subject of this study.

This study will attempt to investigate three major questions related to the RIA technique of determining the sexual origin of a bloodstain. The first question deals with the feasibility of whether commercially available kits are sensitive and selective enough to quantitate the amounts of each steroid present in a specific area of bloodstained material. The quantities that are obtained will then be calculated as a ratio of $\mathrm{T}: \mathrm{E}$ and this final result will be used as a basis for discriminating between male and female samples in both open and blind studies. Secondly, this study will investigate the effect that the age of a bloodstain has on quantifying the steroids in stains up to 60 days old. Finally, the question of whether synthetic steroids, such as those used in oral contraceptive preparations, significantly cross-react in either RIA method will be examined.

Testosterone and estrogen are well suited to indicate sex based on the well established normal average values for each in males and females between 15 and 45 years old. According to the protocols contained in each RIA kit (NEN,

$$
\begin{array}{ll}
1_{\mathrm{ng}-- \text { nanogram }} & \left(10^{-9} \mathrm{gram}\right) \\
\text { pq--picogram } & \left(10^{-1} \mathrm{gram}\right)
\end{array}
$$


1975, 1976) the normal ranges for testosterone in males and females are $3-10 \mathrm{ng}^{1 / \mathrm{ml}}$ and $0-1 \mathrm{ng} / \mathrm{ml} \mathrm{plasma}$, respectively. In a preliminary study only testosterone was assayed in stains prepared from whole blood obtained from ten male and six female volunteers. Although the results from this study demonstrated that sex determination is possible using only testosterone values, it also showed fluctuations in values between individuals of the same sex as well as some overlapping of values between sexes. The concurrent determination of total estrogens in a stain will hopefully stabilize variation between individuals. Also the use of the two markers in a ratio form to indicate sex will eliminate the need to estimate the volume of blood in the stain which is extracted in order to compare amounts per $\mathrm{ml}$ of blood. 


\section{LITERATURE REVIEW}

Genetic markers currently employed in the forensic laboratory include the $\mathrm{ABO}, \mathrm{Rh}$ and $\mathrm{MN}$ antigen-antibody systems, the hemoglobin and haptoglobin polymorphic protein systems, and the phosphoglucomutase (PGM), adenylate kinase (AK), erythrocytic acid phosphatase (EAP), esterase D (ESD), adenosine deaminase (ADA), 6-phosphogluconate dehydrogenase (PGD) and glucose-6-phosphate dehydrogenase (G-6-PD) polymorphic enzyme systems (Culliford, 1971). These systems were chosen for use in the examination of dried bloodstains because they are: 1) genetically controlled; 2) present and detectable in a bloodstain; and 3) supply individualizing information (Garner, 1979).

Research of constant interest in forensic serology is the development of techniques which enable the researcher to detect other marker systems present in a bloodstain. Currently under investigation are the methods which detect markers capable of supplying information about the race, age and sex of the individual who left the stain. Information of this type is especially useful in cases where there are no control samples available, which renders other blood grouping data of little value (Wigmore, 1979). This information can, to a limited extent, inform police investigators about the characteristics of the suspect for whom they are searching. 
Information concerning the race and age characteristics is obtained through the detection of certain variants in the hemoglobin system, which are present in a bloodstain (Garner, 1979). The techniques involved in this method currently allows the forensic serologist to detect the presence of three hemoglobin variants: $\mathrm{HbS}, \mathrm{HbC}$ and $\mathrm{HbF}$. The presence of $\mathrm{HbS}$ and $\mathrm{HbC}$ indicate the stain to be of Negroid origin, whereas the presence of $\mathrm{HbF}$ indicates the blood to be from an infant.

Determination of the sexual origin of a bloodstain became an active subject of research when schwinger in 1971 applied a fluorescent staining technique, which permits the identification of the sex indicating $\mathrm{Y}$-chromosomes in interphase and metaphase nuclei, to cell extracts from a bloodstain. Since this time several other studies have been published which have tested the accuracy or improved on the method. Aragones (1973) found there were many interfering substances in the method used by schwinger and he improved upon the extraction to eliminate those interferences. However, in studies which examine the accuracies of this method in open and blind studies (Schwinger, 1973, and Wigmore, 1979) the method was found to be susceptible to erroneous identifications, caused by interfering fluorescence and the judgment of the observer. This method has been reported to be 40-80\% accurate in blind studies (Schwinger, 1973, and Wigmore, 1979). 
The development of radioimmunoassay (RIA) techniques, which are capable of detecting and quantifying small amounts of specific substances, has provided the forensic serologist with a sensitive and accurate method for confirming the presence of particular marker systems in a bloodstain. With the recent development of new techniques for producing highly specific antibodies against substances of interest to the forensic serologist the RIA method has become a potentially powerful tool.

The application of RIA techniques for steroids in forensic serology was reported independently by Brown (1976) and Stuver (1976) at the 28th annual meeting of The American Academy of Forensic Sciences. In the next year at the 29 th annual meeting, Brown (1977) and Schehr (1977) independently announced the further application of steroid RIA techniques in bloodstains for the purpose of sex identification. In the same year Moller (1977). published data on his application of RIA for detecting morphine in bloodstains.

Those four reports on the use of RIA for quantifying the sex hormones: testosterone, estrogen and progesterone, in bloodstains for the purpose of sex identification, form the basis of this study. Although these three investigators briefly reported on their efforts with this technique there has, as yet, been no formal publication of their methods and results. Since the published data on the results of RIA utilization for the purpose of identifying the sexual 
origin of bloodstains is limited, it is necessary to review the literature dealing with the basic principles of the RIA methodology and especially the specific techniques involved in the RIA of steroids.

Although the methods involved in the RIA technique are generally straightforward it is essential to have a clear idea of the principles involved. An essential component of the RIA method is the antibody. Antibodies were first recognized by Von Behring (1890) when he determined that immunity to diphtheria toxin was dependent upon the ability of a factor in the blood to inactivate the toxin. He proved that. this factor resided in the serum and in 1901 he earned a Nobel prize for his work with antiserum therapy. Since that time antibodies have been used clinically to neutralize biologic macromolecules and recently have been used diagnostically to measure concentrations of these macromolecules. The clinical potential use of antibodies has been greatly expanded with the production of antibodies which are directed against small molecules of therapeutic and diagnostic interest, such as steroids, prostaglandins, thyroid hormones, cyclic nucleotides and certain drugs (Ekins, 1974).

It is the discriminating ability of antibodies to recognize one particular material as distinct from any other which is the basis for their use as an analytical tool in all immunologic methods. Although there is a limitation on an antibody's ability to discriminate between similar structures there are examples where extremely small alterations in the 
structure of a molecule will drastically change its binding to the antibody. Antibodies are not usually preformed in an individual but are produced in response to the entry of the foreign material into the body. Material that induces an immunoresponse is called an immunogen. The substance that is bound by antibodies is called the antigen. Most substances are both immunogen and antigen, but these two properties are distinct and not all antigens have the ability to initiate the formation of antibodies (Thorell, 1978). Antibodies comprise a group of related proteins in blood plasma which are collectively referred to as immunoglobulins. There are five known types of classes of immunoglobulins: IgG, IgM, IgA, IgD and IgE. The basic structure of all immunoglobulins is similar with a pair of large polypeptide chains (heavy chains, H), that consist of 446 amino acids, each associated with a smaller chain (light chain, L) 214 aminoacids long (Roit, 1976). The chains are arranged in a Y-formation and are joined by disulfide bonds. Each immunoglobulin molecule has the ability to bind two antigen molecules, one at each of the two binding sites, which are located at the outer open end of each pair of H-L-chains. Differences in the chemical composition of these two ends of the molecules (the variable portions) are the structural basis for the differences in the binding characteristics of different antibodies. The configuration of this binding site can therefore assume such a variety of forms that it very specifically fits to the surface of any antigenic 
material. The various types of immunoglobulins have somewhat different biologic functions. IgG is the quantitatively dominant immunoglobulin in plasma. It is this class of immunoglobulin that is usually utilized as the binder in immunoassays (Thorell and Larson, 1978).

The antibodies produced in response to an immunogenic stimulus constitute only a very small fraction of the total antibody population occurring in the plasma of an animal. In most assays, however, there is no need to isolate a particular fraction from the other antibodies present, since the assay system only measures the binding of one particular radioactive antigen (Playfair, 1974). Other antibodies present will not interfere in this binding between the labeled antigen and its particular antibody. These mutually associated antigens and antibodies are called homologous antigen and antibody. In certain assay systems, one may utilize antibody that is raised against a different immunogen, in this case the antigen and antibody are called heterologous.

Radioimmunoassay (RIA) and related competitive proteinbinding methods began about 20 years ago as a cumbersome research methodology in two specialist radioisotope centers located in New York and London (Ekins, 1974). These methods represent a common analytical approach of great sensitivity that has been applied to the measurement of more than 200 substances, many of which cannot be assayed by other techniques. It is essentially impossible to exaggerate the 
diversity of applications for this methodology. Virtually every branch of medical and biological research has been affected by these techniques. In particular, endocrinology has been greatly enriched by the new knowledge that has come as a direct result of RIA methods. These methodologies are being introduced into clinical medicine at a rapid rate, and the growing commercial availability of radioassay kits will revolutionize the routine practice of hospital and research laboratories (Challand, 1974).

The term radioimmunoassay was coined by Berson and Yalow (1960) to describe their original methodology. However, this term is.adequate for only a small portion of related assays which are being used today. There has been an effort to select a descriptive word or phrase that would be inclusive of all the various assay types, but it is now felt that the proper individual terms be used for describing a particular assay (Ekins, 1974 and Thorell, 1978). The term radioligand assay will be used interchangeably with RIA.

In order to establish a radioligand assay, three prerequisites must be met: (1) a receptor must be available that specifically binds the ligand (antigen) to be measured; (2) the ligand must be labeled with a radioactive nuclide (radioligand); and (3) separation must be achievable between the ligand bound to the receptor and the ligand that is unbound (Thorell, 1978). The RIA generally consists 
of a competitive type radioligand assay, although a noncompetitive type is sometimes employed.

The competitive assay is the most common type of procedure used in RIA. In this case, the specific receptor is an antibody directed against the ligand (antigen) to be measured. The ligand is injected into a species of animal that sees this substance as foreign (immunogenic) and produces a specific antibody against the ligand. The radioligand is produced by coupling a radioactive nuclide to the ligand as a marker so that the ligand can be measured. The basic principle of RIA is the competition between the radioactive and nonradioactive ligand for a fixed number of antibody sites. This interaction is represented schematically in Figure 1.

If increasing amounts of nonradioactive ligand and a fixed amount of radioactive ligand are allowed to react with a constant amount of antibody, a decreasing amount of radioactive ligand is bound to the antibody. This can be considered as a progressive dilution of radioligand bound to the receptor, or as a progressive dilution of radioactive material with nonradioactive material, thereby reducing the specific activity of the ligand bound to the receptor.

There is usually an incubation period for most assays, during which time the binding reaction between receptor and ligand comes close to equilibrium. This incubation varies in time and temperature requiring anywhere from 30 
Fig. 1. Antibody-Antigen Interaction ${ }^{1}$

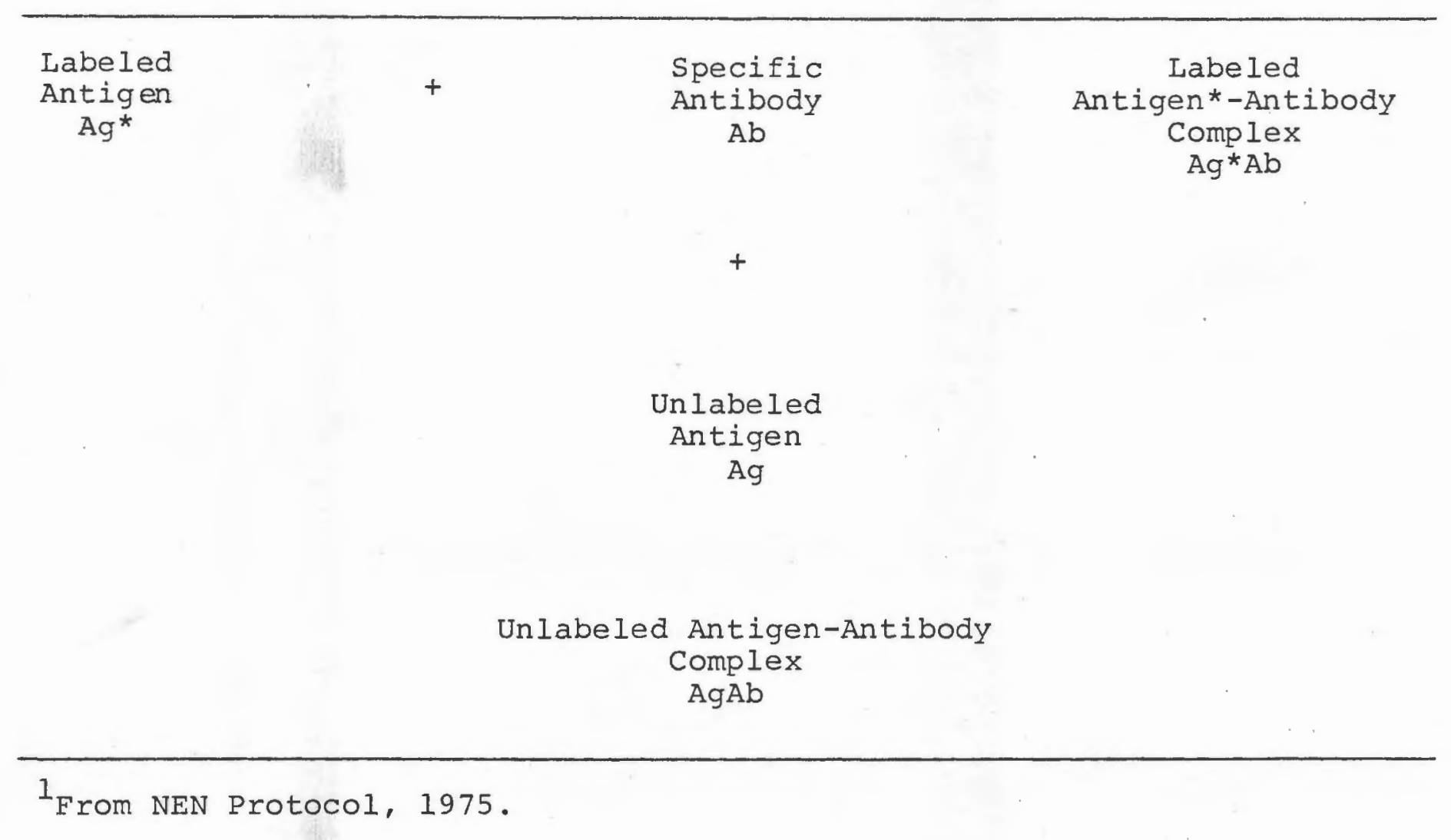


minutes to 24 hours at $37^{\circ} \mathrm{C}$ to $4^{\circ} \mathrm{C}$. For most assays the molar concentration of the receptor is chosen to be about the same order of magnitude as the expected concentration of the ligand in the unknown sample (Parker, 1976). In general, the more dilute the receptor, the more sensitive the assay. At these low concentrations, longer incubation times are necessary in order to achieve a sufficient interaction between ligand and receptor.

After the binding reaction is completed, the separation of free from antibody bound antigen must be achieved in order to determine the partition of the radioactivity. Various techniques have been employed for this purpose (Radcliffe, 1974). In many cases the antibody-antigen complex is precipitated out of solution by the addition of a saturated ammonium sulphate solution. In some circumstances, a second incubation perioà is required, as in the double antibody techniques. When the antigen is a steroid, separation is achieved through selective adsorption of the free antigen onto dextran coated activated charcoal (Kushinsky, 1975). The amount of radioactivity of the bound fraction is then determined. There is an inverse correlation between the amount of radioactivity bound and the concentration of native ligand present in samples. This relationship is usually not linear. In order to be able to measure the amount of ligand present in an unknown biologic sample, such as plasma or urine, the assay must include a standard series of tubes that contain known amounts, 
in sequential increments, of the substance to be assayed (Bangham, 1974). Based on the radioactivity bound to the receptor in these standards, a standard curve is drawn and the amount of unlabeled antigen in a sample can then be determined by interpolation from this curve.

In the noncompetitive assay technique the antibody is usually labeled instead of the ligand. These methods are particularly useful when the ligand cannot be labeled easily, as is the case with most viral antigens (Thorell, 1978). The receptor in this method is coupled to an insoluble, solid phase matrix. An additional set of receptors is labeled with radioactivity. In the initial phase the solid phase receptor is incubated with the sample containing the ligand to be measured until all ligand is bound to this receptor. The second step is to add the additional set of radio-labeled receptors which are soluble. This radioreceptor will adhere to any bound ligand in the preparation. The technique requires that the ligand be sufficiently large enough to have two or more molecular regions that can act as combining sites (divalent or polyvalent). After the second incubation the matrix is washed to remove all nonbound radioactivity. The remaining radioactivity bound to the matrix is measured. A standard curve is constructed by running a series of standards with known incremental amounts of the ligand. The standard curve for this assay is directly proportional to the concentration of ligand present; that is, the larger the amount of ligand 
present, the larger the amount of radioactivity bound to the matrix (Thorell, 1978).

RIA and related clinical methods derive their unique usefulness from their very great sensitivity in relation to other chemical techniques. This sensitivity is related to the extremely sensitive methods for the detection of radioactivity (Ekins, 1974). It is possible to measure the radioactive isotope ${ }^{125} \mathrm{I}$ in quantities as small as $10^{-4} \mathrm{~g}$ (or approximately $10^{-12} \mathrm{M}$ ) with good precision. Since the serum concentrations of most hormones is on the order of $10^{-9}$ to $10^{-10} \mathrm{M}$, detection of hormones at the lowest physiologic concentration is now possible. The quality of any assay is determined by four factors: sensitivity, specificity, precision, and accuracy. Specificity is predominantly a property which is dependent on the receptor. It is the ability of the assay to measure one specific compound and no other. The specificity or lack of it is a major problem in some assays. For many biologically important compounds, a number of compounds exist with similar chemical structures. Steroid hormone assays are a prime example where this problem occurs (James, 1974). There are many steroid derivatives with small differences in structure but with marked physiologic differences. In this situation there are two means of enabling the accurate measurement of a single steroid--the production and selection of highly specific antisera, which requires significant effort especially in the formation of a suitable immunogen. However, this 
cannot be accomplished to the point of exclusion of similar substances and therefore the situation is sometimes improved by chemical separation to isolate the compound of interest from the interfering substances. Solvent extraction, washing procedures and various types of chromatography are the procedures most often used (Thorel1, 1974).

The sensitivity of an assay is limited by two factors: the affinity of the receptor and the specific activity of the radioligand. The affinity of a receptor reflects the energy in binding between the ligand and the receptor, the firmness of the binding. To be able to measure minute amounts of hormones and other biologic compounds with adequate sensitivity the energy of binding has to be very high. This often is the limiting factor for the sensitivity of an RIA (Thore11, 1974).

The specific details involving the production of proper immunogens, specific antibodies, the preparation of the radioactive ligands and the kinetics of the antibody-antigen interaction is beyond the scope of this review. They are clearly detajled in several excellent reviews on RIA and related techiniques (Ekins, 1974; Bangham, 1974; Hunter, 197.4; Playfair, 1974; Parker, 1976; Dawson, 1978, and Thorel1, 1978). Measurement of a substance by the RIA technique depends on its ability to compete with a suitably labeled compound for a binding site. The nature and type of radiolabel influences sensitivity of these assays. The synthesis of compounds containing ${ }^{14} \mathrm{C}$ and ${ }^{3} \mathrm{H}$ suitable as 
markers in a RIA may be expensive, and in addition their specific activity may be so low that undesirably large amounts must be used, which will cause a decrease in the sensitivity of the assay. Manipulations involved in ${ }^{3} \mathrm{H}$ and ${ }^{14} \mathrm{C}$ counting, including sample preparation, quenching corrections, disposal of organic solvents and other difficulties involved in liquid scintillation counting also make use of these types of labels undesirable when alternatives are available. ${ }^{125} I$ and ${ }^{131}$ I have been used for labeling tyrosine conjugates of drugs and labeling of some steroids. They not only produce labels of high specific activity but permit the use of simpler counting methods (Marks, 1974). In pharmacology RIA offers a sensitive, precise and specific method for measuring concentrations of drugs and other significant substances in tissues and blood. This allows for research to be conducted into their distribution, metabolism and pharmacokinetics and, increasingly, for monitoring drug therapy (Marks, 1974). For many drugs there is no other means available to permit accurate measurements under clinical conditions, so that for even for well established drugs such as morphine, virtually no information had been available concerning its concentration in blood under optimum therapeutic conditions. Radioimmunoassay techniques which have currently been developed are helping to eliminate this deficiency.

Although the major obstacle which researchers face in their attempt to develop RIA for proteins and peptides is 
in the isolation of the pure compound, the main problem confronting those developing RIAs for drugs and steroids is in the production of a suitable antisera. These compounds are rendered immunogenic by chemically coupling them to a larger antigenic molecule. This usually involves the formation of a peptide bound between the drug or steroid and the protein, usually but not always, bovine serum albumin (BSA). The point of conjugation often has an important influence on the degree of specificity of the antibody produced; this is especially true with steroids. It has been only in the last five years that highly specific, low cross-reacting, antibodies have been produced utilizing immunogens conjugated at different points on the haptene molecule (Ekins, 1974). Another difficulty encountered when dealing with these compounds is that most cannot be radioiodinated directly. This difficulty is overcome by the use of ${ }^{14} \mathrm{C}$ - or ${ }^{3} \mathrm{H}$-labelled drugs or steroids. Currently drugs or steroids are being coupled to compounds containing a p-hydroxyphenyl group that can be radioiodinated (Hunter, 1974).

As stated ave a major problem with steroid RIA is the cross-reactivity of related steroids with the antibodies produced (James, 1974). For example in the RIA of testosterone the major cross-reacting steroid is dihydrotestosterone which initially showed a 100\% cross-reactivity with antisera manufactured by New England Nuclear (NEN, 1975). This cross-reactivity has recently been reduced to $56 \%$ through production of antisera to a different conjugate. 
This problem is also evident in the RIA of the estrogens. Here the three major estrogens: estradiol, estrone and estriol all cross-react significantly with antisera produced against an estradiol conjugate. When dealing with the measurement of these steroids, it is sometimes necessary, depending on the specificity required, to fractionate the sample extract by column chromatography prior to the assay. With increased antibody specificity the chromatographic step can be eliminated (Castro, 1973; Stah1, 1975 and Sheldon, 1977) which is desirable when dealing with small samples.

Many of the RIAs developed for pharmacology also have a potential for use in the forensic sciences. Those RIAs developed for morphine and opiate alkaloids, lysergic acid derivatives, tetrahydrocannabinol (cannabis), barbituates and other drugs of abuse provide a screening method to detect the particular drug in a suspected abuser, in an overdose case or in blood samples found at a crime scene.

Blood or bloodstains are one of the most frequently encountered types of evidence at crime scenes; especially crimes of the most serious nature such as homocides, assaults and rapes (Saferstein, 1977). The determination of other marker systems in these samples, such as sexual origin, will complement the evidence provided by the identification of the major blood factors. As stated previously the RIA method offers an accurate and sensitive method for sex determination based on the quantity of testosterone and 
estrogens present in a quantity of bloodstained material. Because the steroid molecule is highly stable (Morrison, 1973) it is capable of withstanding the effects of drying in a bloodstain. The proper preparation and extraction of the stain with ether enables the investigator to measure each steroid fairly accurately. The results obtained are then calculated as a ratio for each sample and used as a basis for discriminating between male and female samples.

When working with any RIA method it is essential to know the limits of the antibody being employed, especially in reference to its cross-reactivity with compounds other than the one which is being measured. In working with blood it is not uncommon to have several compounds present in the extract, and therefore in the test system, which are capable of cross-reacting with the antibody and causing an overestimation of the quantity of the compound being measured (James, 1974). This would also be true when working with bloodstains since diethylether will extract from a bloodstain many of the organic soluble steroids present. The cross-reactivity of many of the naturally occurring steroid hormones with the antisera used in this study has been reported by the manufacturer, New England Nuclear (protocols 1975, 1976). However, the question of crossreactivity of this antisera with synthetic steroid hormones, used in oral contraceptives, has not been reported and is undertaken in this study. 
The compounds ethinyl estradiol $\left(\mathrm{EE}_{2}\right)$, ethynodial diacetate, mestranol, norethindrone (NET), norgestrel (Nor-G) and norethylnodrel are the most commonly used synthetics in oral contraceptive preparations (Murad, 1975). The first and third are synthetic estrogens and the remaining four are synthetic progestins. Either group is capable of cross-reacting with the antiserum used in either the testosterone or estrogen assays (see Figures 2 and $2 \mathrm{~A}$ ).

The literature available on these compounds is extensive and a good review of their metabolism has been published (Ranney, 1977). $\mathrm{EE}_{2}, \mathrm{NET}$ and Nor-G are the most representative of this group since mestranol is converted to $\mathrm{EE}_{2}$ and the others to $\mathrm{NET}$ in vivo. Reports concerning the plasma concentration of these drugs after administration is limited. This information is necessary in order to perform significant studies dealing with cross-reactivity. Verma (1975) reports the plasma levels to range from 144 to $248 \mathrm{pg} / \mathrm{ml}$ after 6 hours in women receiving 50 ug of $\mathrm{EE}_{2}$ or mestranol, through the use of a competitive protein binding radioassay for $\mathrm{EE}_{2}$. RIA procedures developed for NET (Nygren, 1974 and Stanczyk, 1978) show plasma levels to rise and fall rapidly and attain peak levels of approximately $15 \mathrm{ng} / \mathrm{ml}$ within 1.5 hours after ingestion of a $1 \mathrm{mg}$ dose. Finally, Brenner (1977) reported, levels of Nor-G, as determined by RIA, to range between $8-12 \mathrm{ng} / \mathrm{ml}$ plasma in women receiving 500 ug per day for twenty-one days. 
Fig. 2 Testosterone and Synthetic Progestins
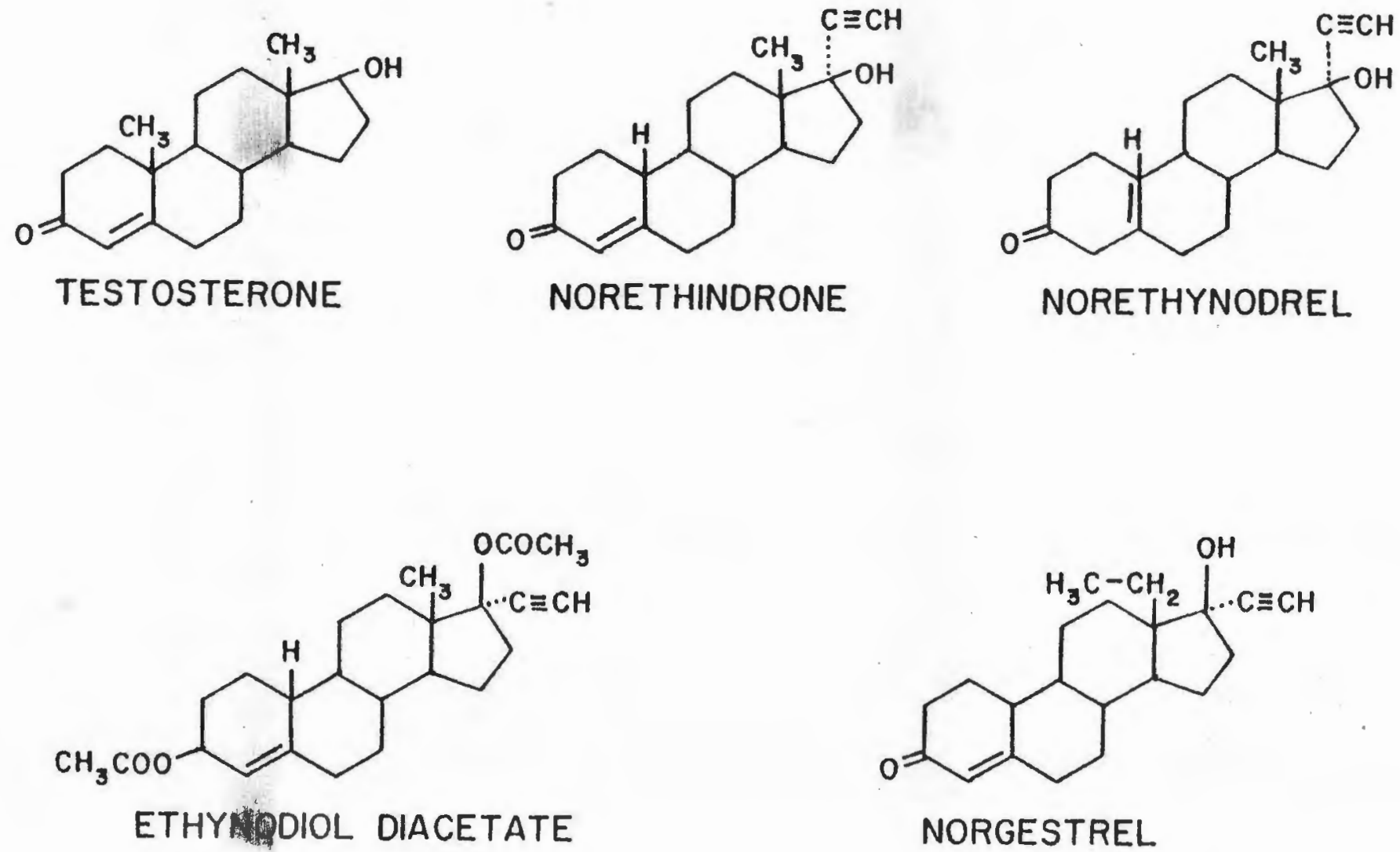
Fig. 2A Endogenous and Synthetic Estrogens
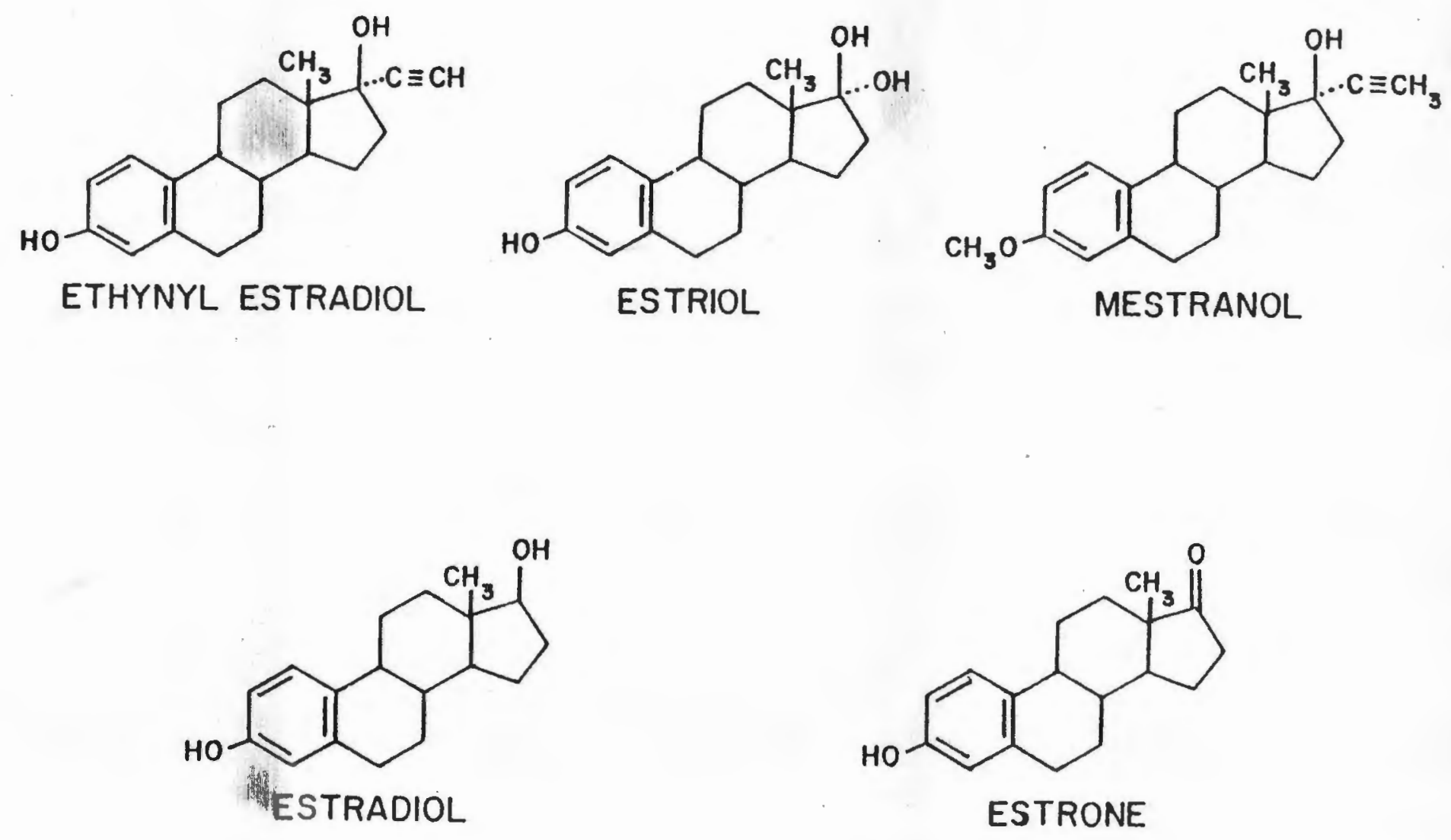
The normal daily dose for each of these compounds as reported by Murad (1975) are as follows: $\mathrm{EE}_{2}$ : 20 ug to looug with an average of 50ug; NET: 500ug to 10,000ug with an average of 1,000us; Nor-G: 75 ug and 500 ug.

In addition to their cross-reactivity potentials these compounds could affect the assay in another way. Briggs (1976) has reported that the administration of these synthetic hormones cause changes in the estradiol fluctuations seen in the female cycle. In women being administered these preparations there are no estradiol peaks observed, due to $\mathrm{LH}$ suppression, although basal levels remain the same. These drugs affect progestrone levels in the same manner. Testosterone levels have been observed to increase slightly. In essence these drugs could cause an over or underestimation of the actual $\mathrm{T}$ and/or $\mathrm{E}$ levels present in a stain from a female who is taking such medication. 
III. EXPERIMENTAL

During the course of the study blood samples were obtained from two groups of volunteers. The first group of twenty-four samples, obtained from twelve male and twelve females, constituted an open study in which the sex of each individual sample was known. The second group of sixteen samples, eight males and eight females, constituted a single-blind study where the number of male and female samples were known but the sex of each individual sample was not known until all assays were completed. The volunteers ranged in age between 18 and 27 years.

All blood samples were drawn by a qualified medical technologist into $7 \mathrm{ml}$ EDTA vacutainer tubes to prevent coagulation. From each individual blood sample twelve whale bloodstains were prepared by absorbing $0.1 \mathrm{ml}$ of whole blood onto $2 \times 2 \mathrm{~cm}$ square pieces of white cotton cloth and allowing them to dry completely on a large flat piece of clear glass. Each greap of stains was then stored in 1 a diseled plastic bags. Assays were run simultaneously for testosterone and estrogen at three different intervals from the time of staining. The first assay was performed 48-72 hours after the stains were made. The second and third assays were subsequently conducted at one and two month intervals. 
The equipment, reagents and space required for the completion of this study were made available in the Department of Pharmacology and Toxicology at the University of Rhode Island. Special chemicals such as BSA, Fr. IV; gamma globulin, Fr. II; norit A, neutral; and dextran T-70 were obtained from Sigma Chemical Company, St. Louis, Mo. All chemicals utilized were of reagent grade quality. Anesthetic grade ether, used for extraction of the samples, was obtained from the Department of Medicinal Chemistry at the University of Rhode Island. The pure synthetic steroids used in the cross-reactivity studies were supplied courtesy of Ortho Pharmaceutical Corporation, Raritan, N.J. (Ethynyl Estradiol, Mestranol and Norethindrone); Searle and Co., San Juan, Puerto Rico (Ethynodiol Diacetate and Norethynodrel); and Wyeth Laboratories, Inc., Philadelphia, Pa. (Ethinyl Estradiol and d1-Norgestrel).

Commercial RIA kits for testosterone and estrogens, sufficient for 500 tubes each, were obtained from New England Nuclear Biomedical Assay Laboratories, North Billerica, Masf Each RIA kit consists of five vials of lyophilized antiserum, one vial each of tritium labeled steroid in organic solvent and steroid standard in buffer and a protocol which outlines the preparation of the components and the basics for their use in a RIA determination in plasma or urine samples. The methods described for this study follow those outlined in the protocols with some modifications. 
The buffer and dextran coated charcoal systems used in each assay were freshly prepared prior to each assay. Their formulations are shown in Table 1 . Prior to the use of the antisera in the RIA determinations they had to be reconstituted with the respective assay buffer to obtain a specific titer. The following rapid procedure was used for the titer determination and reconstitution of each antiserum.

Five and $2.5 \mathrm{mls}$ of the proper assay buffer were added to the lyophilized vials of testosterone and estradiol antisera, respectively. The vials were gently inverted several times over a 15-30 minute period to insure complete dissolution. Fifty and $25 \%$ dilutions were prepared by adding 0.15 and $0.30 \mathrm{ml}$ of assay buffer to 0.15 and $0.10 \mathrm{ml}$ aliquots of the concentrates. Eight $12 \times 75 \mathrm{~mm}$ disposable glass tubes were prepared in accordance with Table 2 for each antiserum. The tubes were mixed on a vortex genie and incubated at $4{ }^{\circ} \mathrm{C}$ for 2.4 hours. They were then placed in an ice bath and the proper cold dextran coated charcoal suspension (under enstant stirring) was added to all except tubes 1 and 2. The tubes were allowed to stand, on ice, for 5 minutes and then centrifuged under refrigeration at $2700 \mathrm{rpm}$ for 30 minutes. After centrifuging the tubes were put on ice and $0.5 \mathrm{ml}$ of the supernatant was transferred into scintillation vials containing $10 \mathrm{ml}$ of Hydromix ${ }^{1}$

\footnotetext{
${ }^{1}$ Hydromix is a trademark of Yorktown Research, Hackensack, , NJ .
} 
Table I

Solutions for RIA

Testosterone System

Stock Solution

$\begin{array}{lr}\mathrm{NaH}_{2} \mathrm{PO}_{4} \cdot \mathrm{H}_{2} \mathrm{O} & 13.8 \mathrm{~g} \\ \mathrm{NaN}_{3} & 2.0 \mathrm{~g} \\ \text { Dissolve in } 900 \mathrm{ml} \text { of } & \\ \text { distilled water. } & \\ \text { Adjust pH to } 7.4 \pm 0.1 & \pm \\ \text { with IN } \mathrm{NaOH} \text { then } \\ \text { q.s. to } 1000 \mathrm{ml} \text { with } \\ \text { distilled water. }\end{array}$

Assay Buffer

\section{BSA Fr.V}

Stock solution

$5.0 \mathrm{~g}$

Dilute to $1000 \mathrm{ml}$

with distilled water.

\section{Estrogen System}

Assay Buffer

$\mathrm{NaH}_{2} \mathrm{PO}_{4} \cdot \mathrm{H}_{2} \mathrm{O}$

$\mathrm{Na}_{2} \mathrm{HPO}_{4} \cdot 7 \mathrm{H}_{2} \mathrm{O}$

$\mathrm{NaCl}$

$\mathrm{NaN}_{3}$

४-Globulin Fr. II

Dissolve in $900 \mathrm{ml}$

of distilled water.

Adjust $\mathrm{pH}$ to 7.0 0.1

with $1 \mathrm{~N} \mathrm{NaOH}$ then

q.s. to $1000 \mathrm{ml}$ with

distilled water.

\section{Charcoal Solution}

$\mathrm{NaCl}$

Dextran $\mathrm{T}-70$

$0.900 \mathrm{~g}$

Norit A, neutral

Dissolve in 100ml of

stock solution.
$0.025 \mathrm{~g}$

$0.250 \mathrm{~g}$
Charcoal Solution

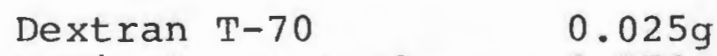

$0.025 \mathrm{~g}$

Norit A, neutral

Dissolve in $100 \mathrm{ml}$

assay buffer solutión. 
Table 2

Antiserum Titer Determination

\begin{tabular}{|c|c|c|c|c|c|}
\hline \multirow[b]{2}{*}{ Tubes } & \multirow{2}{*}{$\begin{array}{l}\text { Assay } \\
\text { Buffer }\end{array}$} & \multirow[b]{2}{*}{ Assay Tracer } & \multicolumn{3}{|c|}{ Dilution of Antiserum } \\
\hline & & & thailuted & $1: 1$ & $1: 3$ \\
\hline 1,2 & $1.0 \mathrm{mI}$ & $0.1 \mathrm{ml}$ & -- & -- & -- \\
\hline 3,4 & $0.1 \mathrm{mI}$ & $0.1 \mathrm{ml}$ & $0.1 \mathrm{ml}$ & -- & -- \\
\hline 5,6 & $0.1 \mathrm{ml}$ & $0.1 \mathrm{mI}$ & -- & $0 . \operatorname{lml}$ & -- \\
\hline 7,8 & $0.1 \mathrm{ml}$ & $0.1 \mathrm{mI}$ & -- & -- & $0.1 \mathrm{ml}$ \\
\hline
\end{tabular}


scintillation cocktail. The vials were capped tightly, vortexed and counted for tritium for ten minutes each. The percent radioactivity bound in tubes 3 through 8 was then determined by reference to the average cpms of tubes 1 and 2. By plotting the dilution of antiserum versus the percent radioactivity bound (Figure 3), the proper dilution to obtain 40-50\% binding was determined. The remainder of the original concentrate, and other vials of lyophilized antiserum with the same lot number, were diluted to the appropriate volume. The reconstituted antiserum was stored at $4^{\circ} \mathrm{C}$ and mixed well prior to use in each assay. In this form the antiserum is stable for approximately two months. Indications of deterioration are a sharp drop in binding from previous levels or a significant change in the sensitivity of the standard curve (McArthur, 1970 and NEN, 1975).

The tritium labeled tracer was supplied in a benzeneethanol (9:1) mixture at a specific activity of 305-450 $\mathrm{DPM} / \mathrm{pg}$, or $1.5 \mathrm{uCi} / \mathrm{ml}$, or approximately $1000 \mathrm{cpm} / \mathrm{ul}$. The recovery tracers prepared by drying down an appropriate aliquot of the tracer in a glass vial and redissolving it in assay buffer to obtain 700-1000cpm/0.1ml. The assay tracer was prepared in a similar manner to obtain approximately $4000 \mathrm{cpm} / 0.1 \mathrm{ml}$ for the testosterone assay and 5000 $\mathrm{cpm} / 0 . \mathrm{lml}$ for the estrogen assay.

The concentrated and diluted tracers were stored tight ly capped at $4^{\circ} \mathrm{C}$. This labeled antigen is stable for 
at least two months under these conditions. Indications of deterioration are decreased binding, decreased recovery, or an increase in the RIA blank (nonspecific binding) (NEN, 1975).

Stock solutions of testosterone and estradiol were supplied in assay buffer at a concentration of $100 \mathrm{ng} / \mathrm{ml}$. This material is stable for at least three months when stored at $4^{\circ} \mathrm{C}$. A standard curve must be run with each assay to cover the range of concentrations anticipated in the unknowns. A series of standards were prepared from the stock solution by diluting $0.1 \mathrm{ml}$ of stock to $1.0 \mathrm{ml}$ with assay buffer to obtain a concentration of 1 ng/0.1ml. This was labeled solution $A$ and further dilutions were made up, as outlined in Table 3, to provide a range of standards appropriate for the assays.

The extraction of the artificially prepared bloodstains were carried out in labeled $13 \times 100 \mathrm{~mm}$ disposable test tubes. From the twelve $2 \times 2 \mathrm{~cm}$ squares for each individual one was extracted for the testosterone assay and three were extracted for thestrogen assay due to the nearly threefold differences in plasma concentration (NEN, 1975). The remaining pieces were used in the age study assays. Prior to each extraction, $0.1 \mathrm{ml}$ of the appropriate recovery tracer was added to the pieces of cloth in the tubes and allowed to dry. The stains were then extracted with 2,2 and lml portions of an organic solvent. Initially, methylene chloride was used for the testosterone extraction and 
Table 3

\section{Standard Solutions}

\begin{tabular}{cccc} 
Solution & Aliquot $(\mathrm{ml})$ & $\begin{array}{c}\text { Assay } \\
\text { Buffer }(\mathrm{mi})\end{array}$ & $\begin{array}{c}\text { Concentration } \\
(\mathrm{ng} / 0.1 \mathrm{mI})\end{array}$ \\
\hline A & 0.1 stock & 0.9 & 1.00 \\
B & $0.5 \mathrm{~A}$ & 0.5 & 0.50 \\
C & $0.6 \mathrm{~B}$ & 0.4 & 0.30 \\
D & $0.6 \mathrm{C}$ & 0.3 & 0.20 \\
E & $0.5 \mathrm{D}$ & 0.5 & 0.10 \\
F & $0.5 \mathrm{E}$ & 0.5 & 0.05 \\
G & $0.6 \mathrm{~F}$ & 0.4 & 0.03 \\
H & $0.6 \mathrm{G}$ & 0.3 & 0.02 \\
I & $0.3 \mathrm{H}$ & 0.3 & 0.01 \\
J & $0.3 \mathrm{I}$ & 0.3 & 0.005 \\
\hline
\end{tabular}


diethyl ether for the estrogen extraction. However, the recovery with diethyl ether was greater than recovery with methylene chloride, so all future extractions were carried out using diethyl ether. The extract portions were then pooled for each sample into corresponding $13 \times 100 \mathrm{~mm}$ test tubes. The organic solvent was then taken to dryness either in a vortex evaporator at $37^{\circ} \mathrm{C}$ under vacuum or by a stream of nitrogen gas. Two mls of absolute ethanol was then added to each tube and they were vortexed for complete dissolution.

The reconstituted samples were then divided into aliquots for use in the recovery determinations and the RIAs. A $0.5 \mathrm{ml}$ aliquot was transferred to and dried down directly in scintillation vials. Ten mls of Hydromix ${ }^{1}$ scintillation cocktail and $0.1 \mathrm{ml}$ of the appropriate buffer were then added, the vials were capped, vortexed and counted for ten minutes each. The cpms obtained for each were compared with the average cpms for two vials which contained $0.1 \mathrm{ml}$ of the recovery tracer and $10 \mathrm{ml}$ of scintillation cocktail, the total recov standard, to determine the percent of steroid recovery.

The actual assays were carried out in $12 \times 75 \mathrm{~mm}$ disposable test tubes (RIA tubes). Each sample was prepared in duplicate by transferring two aliquots to labeled duplicate

\footnotetext{
${ }^{1}$ Aquassure scintillation cocktail was used when Hydromix was unavailable. Aquassure is a trademark of the New England Nuclear Corporation, Boston, Mass. 02118.
} 
RIA tubes. These samples were dried down by a stream of nitrogen. Total count, blank, zero standard, steroid standards and the sample tubes were then prepared as outlined in Table 4: The incubation of all tubes at $4^{\circ} \mathrm{C}$ lasted for 18-20 hours. Following incubation the tubes were placed in an ice bath and the proper amount of the appropriate dextran coated charcoal solution was added to only as many tubes as could be centrifuged at one time. The charcoal solution is not added to any of the total count tubes. After a five minute period, on ice, these tubes were centrifuged at $4^{\circ} \mathrm{C}$ for 30 minutes at $2700 \mathrm{rpm}$ in a bucket-type centrifuge. Upon completion of centrifugation equal portions of supernatant from each tube were placed in labeled scintillation vials containing $10 \mathrm{mls}$ of Hydromix ${ }^{1}$ scintillation cocktail. The vials were tightly capped, vortexed and counted for tritium for 10 minutes each.

A total of fourteen separate assay's were conducted using this procedure. Three testosterone and three estrogen assays were performed in each of the open and single blind studies at 2, 30 and 60 days after the preparation of the bloodstained samples. Two assays were conducted to test the cross-reactivity of certain synthetic steroids with the testosterone and estradiol antiserums.

After the completion of both the open and single-blind studies the cross-reactivity study, concerning the synthetic

\footnotetext{
${ }^{1}$ Aquassure scintillationcocktail was used when Hydromix was unavailable. Aquassure is a trademark of the New England Nuclear Corporation, Boston, Mass. 02118 .
} 
Table 4

$\underline{\text { RIA PROTOCOL }}$

\begin{tabular}{|c|c|c|c|c|c|c|c|c|c|}
\hline \multirow{2}{*}{ Tube ${ }^{1}$} & \multicolumn{2}{|c|}{$\begin{array}{c}\text { Assay } \\
\text { Buter (ml) }\end{array}$} & \multicolumn{2}{|c|}{$\begin{array}{l}\text { Standard or } \\
\text { sample (ml) }\end{array}$} & \multirow{2}{*}{$\begin{array}{l}\text { Assay } \\
\text { Tracer } \\
\text { Both }\end{array}$} & \multicolumn{2}{|c|}{$\begin{array}{l}\text { Anti- } \\
\text { serum } \\
\text { (ml) }\end{array}$} & \multicolumn{2}{|c|}{$\begin{array}{c}\text { Charcoal } \\
\text { Suspension }\end{array}$} \\
\hline & & $\mathrm{E}$ & $T$ & $E$ & & $\mathrm{~T}$ & $E$ & $T$ & $\mathrm{E}$ \\
\hline Total Amount & 1.0 & 1.20 & -- & -- & 0.1 & -- & -- & -- & -- \\
\hline Blank & 0.2 & 0.15 & -- & -- & 0.1 & -- & -- & 0.8 & 1.0 \\
\hline Zero std. & 0.1 & 0.10 & -- & -- & 0.1 & 0.1 & 0.05 & 0.8 & 1.0 \\
\hline Al1 stds. 4 & -- & -- & 0.1 & 0.1 & 0.1 & 0.1 & 0.05 & 0.8 & 1.0 \\
\hline All Samples & 0.1 & 0.10 & $(0.5)^{5}$ & $(0.6)^{5}$ & 0.1 & 0.1 & 0.05 & 0.8 & 1.0 \\
\hline
\end{tabular}

${ }^{1}$ All tubes run in duplicate.

2 The assay tracers were prepared at 4000 cpms for the open and single-blind studies and at $10^{4} \mathrm{cpms}$ for the cross-reactivity study.

${ }^{3}$ Antiserum is added last in every case. All tubes were incubated at $4^{\circ} \mathrm{C}$ for approximately 24 hours.

${ }^{4}$ Standards B-J them Table 3 were used in all three studies. The concentrations of synthetic stero shown in Tables 5 and 6 were treated as standards in the crossreactivity study.

${ }^{5}$ Dried down aliquots of the ethanol reconstituted extracts. 
steroids mentioned previously, was undertaken. The six synthetic steroids supplied to us, through the various pharmaceutical companies mentioned, were each weighed to the nearest $0.0 \mathrm{Img}$. Each was dissolved in an appropriate volume of a benzene:ethanol (9:1) solution to obtain a concentration of $\mathrm{lmg} / \mathrm{ml}$. These stock solutions were appropriately labeled and serially diluted as outlined in Tables 5 and 6 to give ranges of concentrations which would be suitable for use in the cross-reactivity studies.

The detemination of the cross-reactivity of these synthetic steroids was accomplished in two separate assays with the testosterone and estradiol antiserums. Each of the six steroids, in the concentration ranges shown in Table 5, were tested against the estradiol antiserum. The assay of these compounds were run concurrently with a set of estradiol standards prepared as shown in Table 3. In the crossreactivity studies with the testosterone antiserum, there was a need to conserve some of the components of the testosterone RIA kit and therefore only three representative synthetic steroidst $\mathrm{EE}_{2}$, NET and norgestrel were testad. The ranges of concentrations shown in Table 6 were assayed concurrently with a set of testosterone standards (Table 3). The protocol for the cross-reactivity study is the same as outlined in Table 4 for the other two studies. 
Table 5

Synthetic steroid Standards for the Estradiol Cross-Reactivity study

\begin{tabular}{|c|c|c|c|c|}
\hline Solution & Aliquot & (ml) & $\begin{array}{c}\text { Assay } \\
\text { Buffer (mI) }\end{array}$ & $\begin{array}{c}\text { Concentration } \\
(\mathrm{ng} / 0.1 \mathrm{ml}) \\
\end{array}$ \\
\hline A & $0.1 \mathrm{ml}$ & stock $^{1}$ & 10.0 & 1000.0 \\
\hline B & 0.5 & A & 0.5 & 500.0 \\
\hline C & 0.6 & B & 0.4 & 300.0 \\
\hline $\mathrm{D}$ & 0.6 & C & 0.3 & 200.0 \\
\hline$E$ & 0.5 & D & 0.5 & 100.0 \\
\hline $\mathrm{F}$ & 0.5 & $E$ & 0.5 & 50.0 \\
\hline G & 0.6 & $\mathrm{~F}$ & 0.4 & 30.0 \\
\hline $\mathrm{H}$ & 0.6 & G & 0.3 & 20.0 \\
\hline$I$ & 0.5 & $\mathrm{H}$ & 0.5 & 10.0 \\
\hline$J$ & 0.5 & $I$ & 0.5 & 5.0 \\
\hline $\mathrm{K}$ & 0.6 & $\mathrm{~J}$ & 0.4 & 3.0 \\
\hline$L$ & 0.6 & $\mathrm{~K}$ & 0.3 & 2.0 \\
\hline \multicolumn{5}{|c|}{$\begin{array}{l}\text { utions of each of the six synthetic } \\
\text { concentration of } 1 \mathrm{mg} / \mathrm{ml} \text { in a benzene: } \\
\text { solution were dried down prior to addi- }\end{array}$} \\
\hline
\end{tabular}


Table 6

Synthetic steroid standards for Testosterone Cross-Reactivity study

Ethinyl Estradiol

\begin{tabular}{cccc} 
Solution & Aliquot $(\mathrm{ml})$ & $\begin{array}{c}\text { Assay } \\
\text { Buffer }(\mathrm{ml})\end{array}$ & $\begin{array}{c}\text { Concentration } \\
\text { (ng/0.1 ml) }\end{array}$ \\
\hline A & 0.1 Stock $^{1}$ & 0.9 & 0.50 \\
B & $0.6 \mathrm{~A}$ & 0.4 & 0.30 \\
C & $0.6 \mathrm{~B}$ & 0.3 & 0.20 \\
D & $0.5 \mathrm{C}$ & 0.5 & 0.10 \\
E & $0.5 \mathrm{D}$ & 0.5 & 0.05
\end{tabular}

Norethindrone and Norgestrel
A
0.1 stock $^{2}$
4.9
20.0
B
0.75 stock
4.925
15.0
C
$0.5 \AA$
0.5
10.0
D
$0.5 \mathrm{C}$
0.5
5.0
E
$0.4 \mathrm{D}$
0.6
2.0

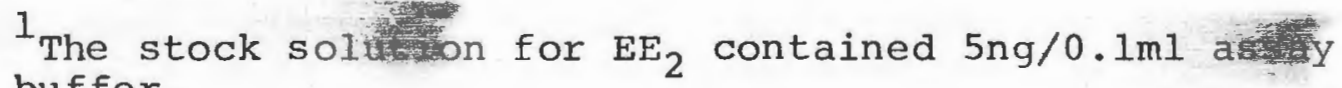
buffer.

2 The stock solutions for NET and Norgestrel contained $1000 \mathrm{ng} / 0.1 \mathrm{ml}$ assay buffer. 
IV . RESULTS

The original data obtained from the various studies were in terms of counts per minute (cpm) of radioactivity as determined in a Packard Tri-Carb Liquid Scintillation Spectrometer Model 3310. CPMs for duplicate tubes were averaged and all counts were corrected for background interference by subtracting the blank values obtained for the same counting session. The appropriate net cpms were then manipulated through the use of the equations shown in Appendix $A$ to determine: 1. The fractional recovery of testosterone (T) or estrogen (E) from the extraction of the bloodstained samples (Eq. I), 2. the percent radioactivity bound in the assay of the standards, samples and synthetic steroids (Eq. II), and 3. the amount of each steroid (ng) per bloodstained sample (Eq. III).

Titer determinations were made on three different lots of antiserum (one $T$ and two E). Duplicates were averaged, corrected for batkground and the percent bound detmined by reference of the antiserum containing samples to the total count samples. The percent bound was then plotted against the antiserum dilution to produce the graphs shown in Figure 3. The various lots of antiserum were diluted, as needed, to those proportions on the proper curves which produce between 40 and $50 \%$ binding. 
Fig. 3 Antiserum Dilution Curves
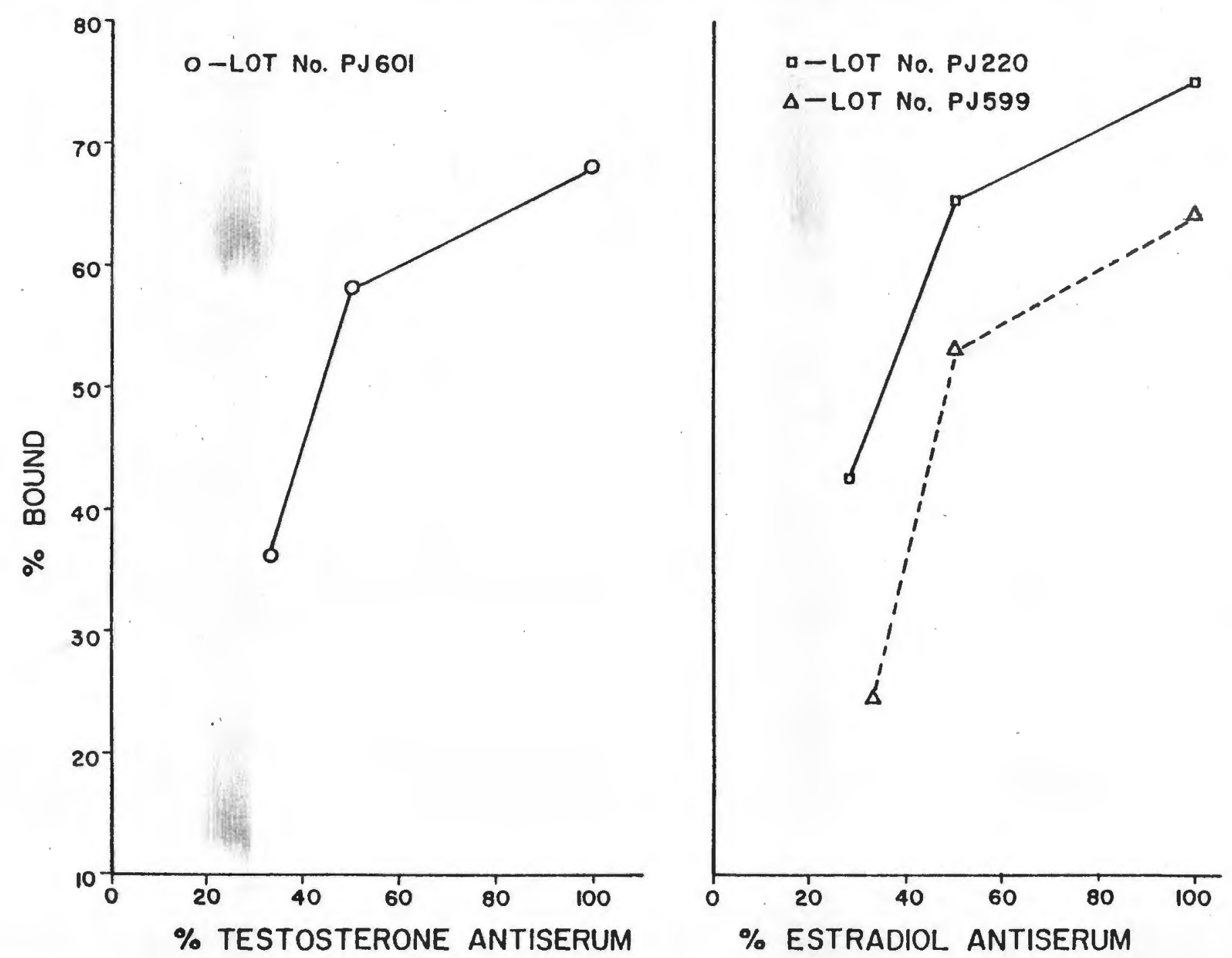

$\%$ ESTRADIOL ANTISERUM 
Fractional recoveries were determined for each sample assayed within the open and single-blind studies (Eq. I). The individual values obtained were used in the determination of the actual amount of $\mathrm{T}$ or $\mathrm{E}$ present in the original bloodstained sample (Eq. III). The average fractional recovery and standard error (S.E.) were determined for each of these assays. These averages, in Table 7, show the overall recovery of $m$ and $E$ to be $64.3 \%$ and $68.8 \%$, respectively.

The percent of radioactivity bound was determined for the standards. samples and synthetic steroids in every assay (Eq. II). The values for each standard were plotted against the corresponding log-dose of the steroid (ng) on semi-logarithmic paper. The resulting standard curves are displayed in Figures 4-15. Figures 4-13 correspond to the age group of the samples assayed in the open and singleblind studies and are labeled accordingly. Figures 8 and 9 were used for both the 60 day old samples of the open study and the 2 day old samples of the single-blind study since the assays for these groups were performed concurrently. The standard cylyes for the cross-reactivity studiog (Figures 14 and 15) were plotted along with the curves obtained for the synthetic steroids tested, since each synthetic steroid was treated as a standard.

Amounts of $\mathrm{T}$ and $\mathrm{E}$ in the extract aliquot assayed for each sample were determined by interpolation from the proper standard curve. These values were adjusted to give 


\section{Table 7 \\ Average Fractional Recovery and Standard Errors Open study}

Testosterone Extract

$$
\begin{aligned}
& 0.465 \pm 0.010 * \\
& 0.745 \pm 0.019 \\
& 0.922 \pm 0.014
\end{aligned}
$$

Estrogen Extract

$$
\begin{aligned}
& 0.751 \pm 0.004 \\
& 0.727 \pm 0.006 \\
& 0.960 \pm 0.012
\end{aligned}
$$

$\underline{\text { Single-Blind Study }}$

Testosterone Extract

$$
\begin{aligned}
& 0.757 \pm 0.018 \\
& 0.173 \pm 0.009 \\
& 0.798 \pm 0.017
\end{aligned}
$$

Estrogen Extract

$$
\begin{aligned}
& 0.684 \pm 0.033 \\
& 0.274 \pm 0.013 \\
& 0.732 \pm 0.027
\end{aligned}
$$

* * This extraction was performed using methylene chloride. All other extractions were performed using diethyl ether. 


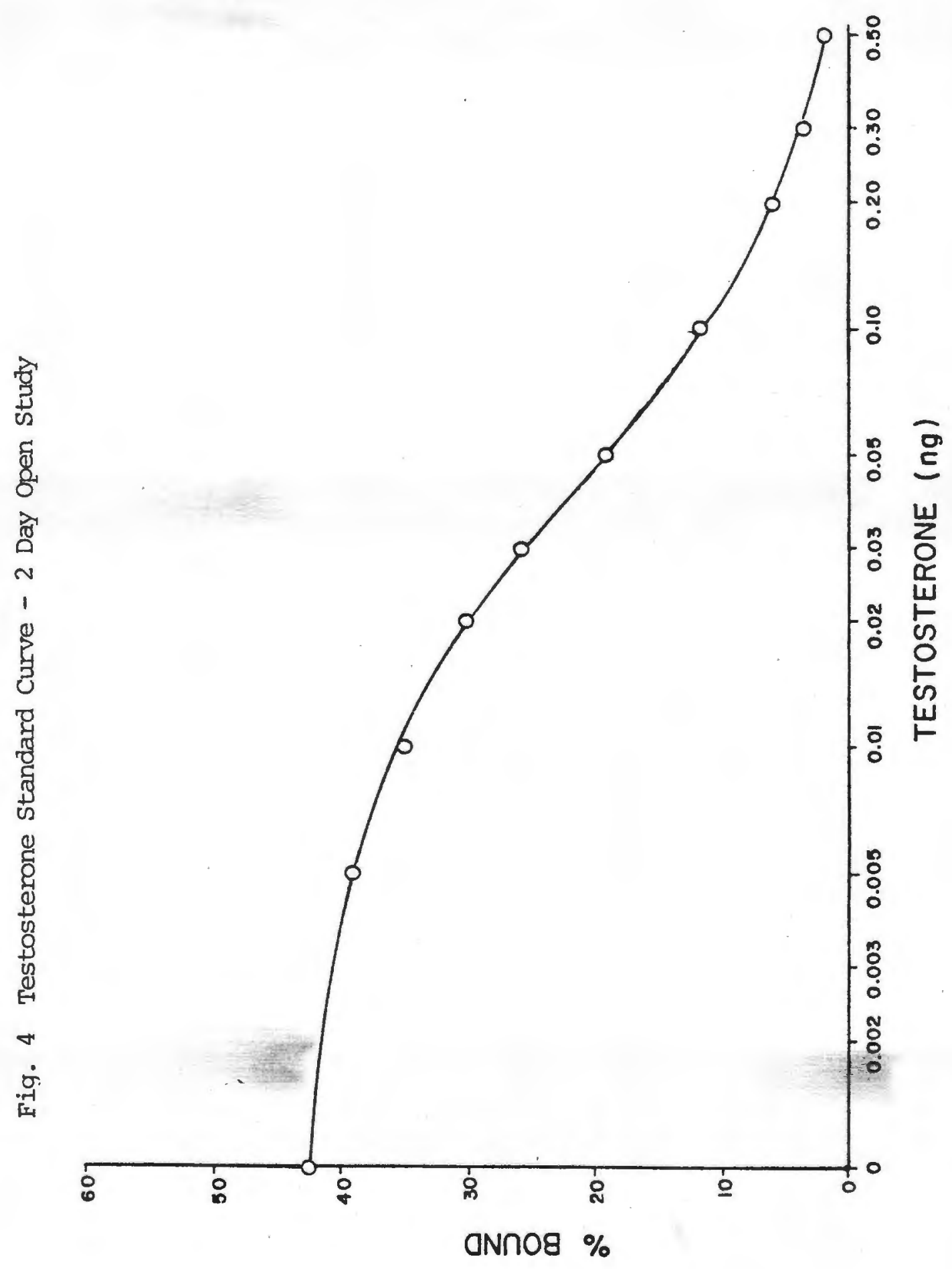




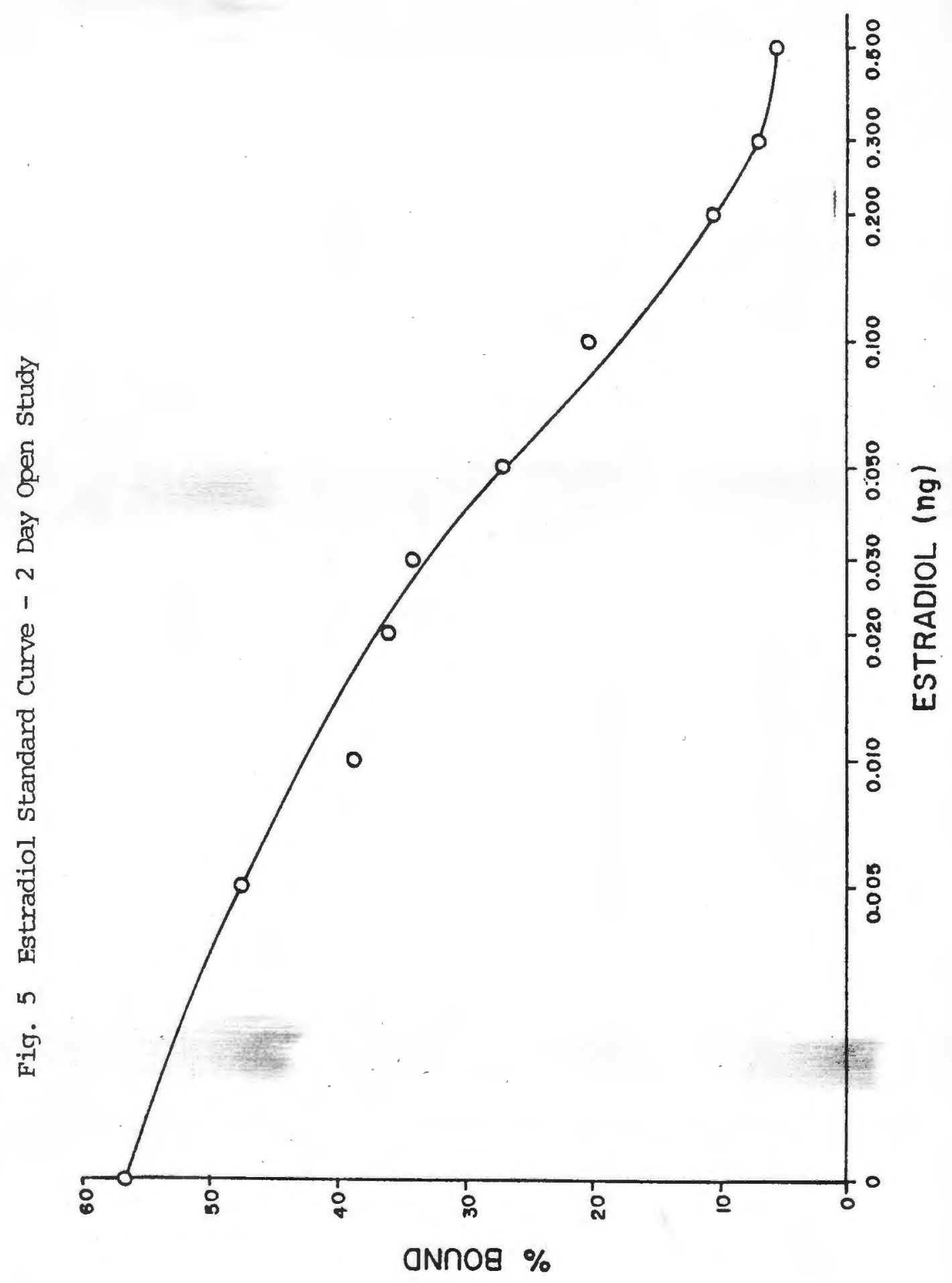


Fig. 6 Testosterone Standard Curve - 30 Day Open Study

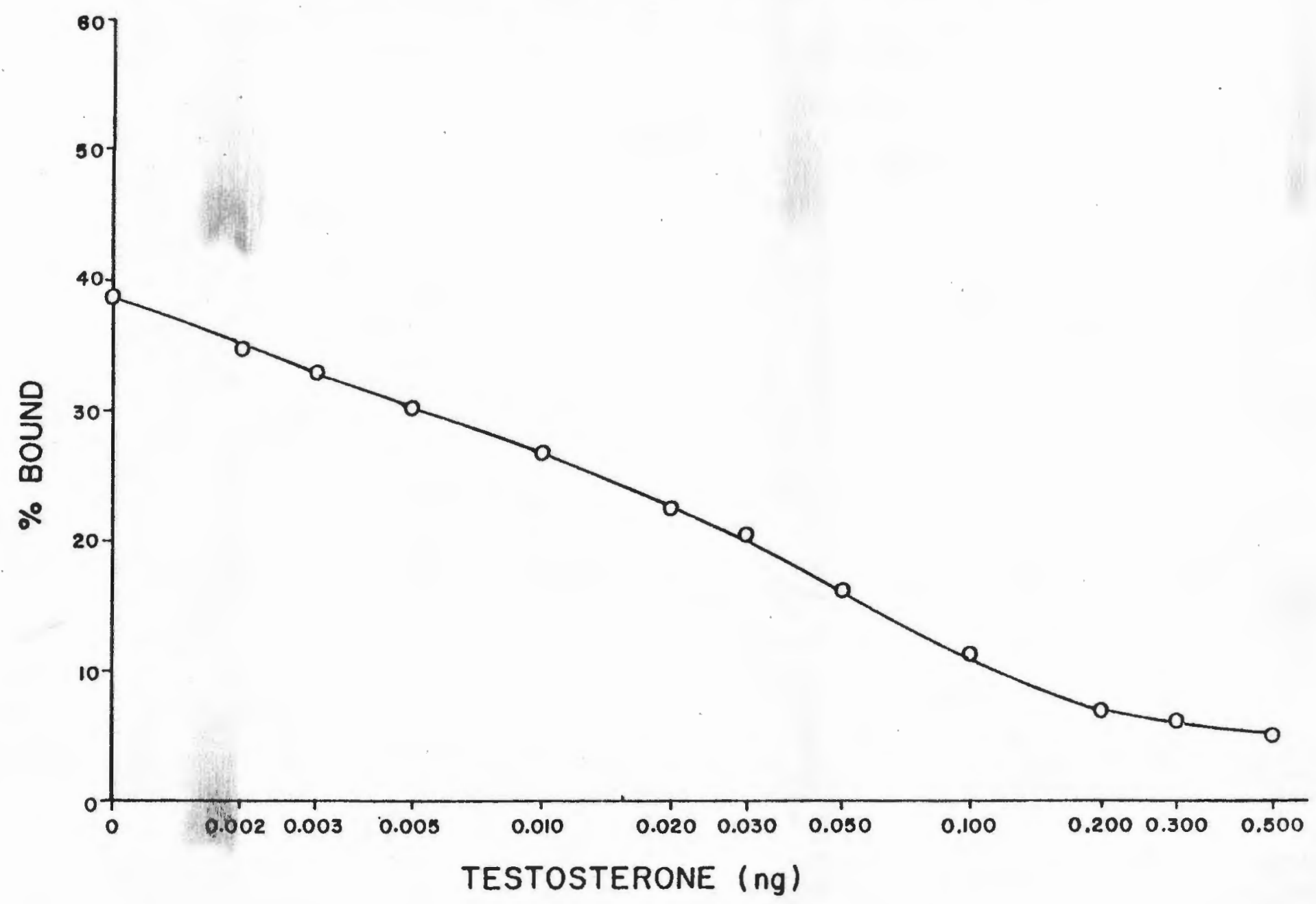


Fig. 7 Estradiol Standard Curve - 30 Day Open Study

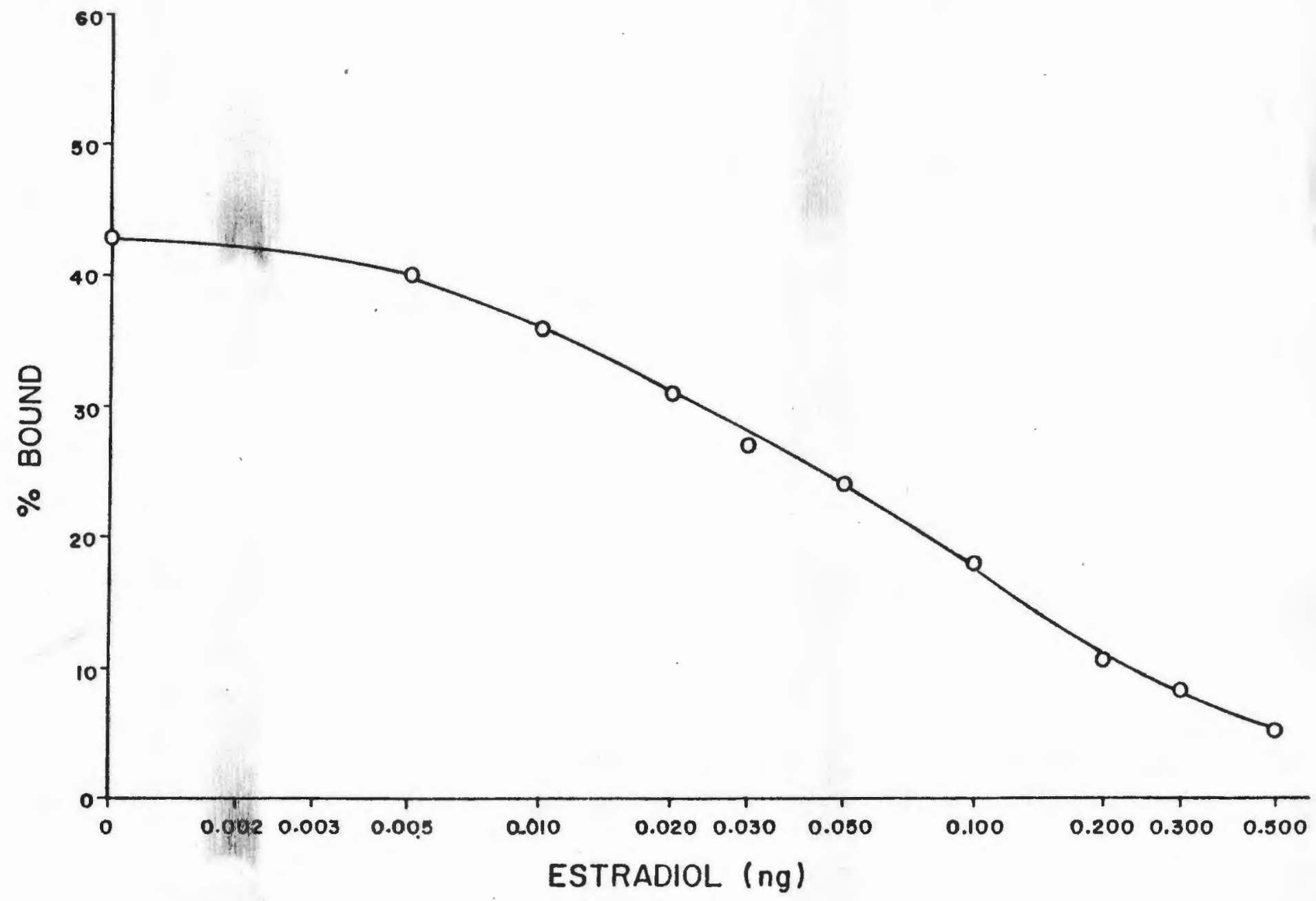


Fig. 8 Testosterone Standard Curve - 60 Day Open Study and 2 Day Single-Blind Study

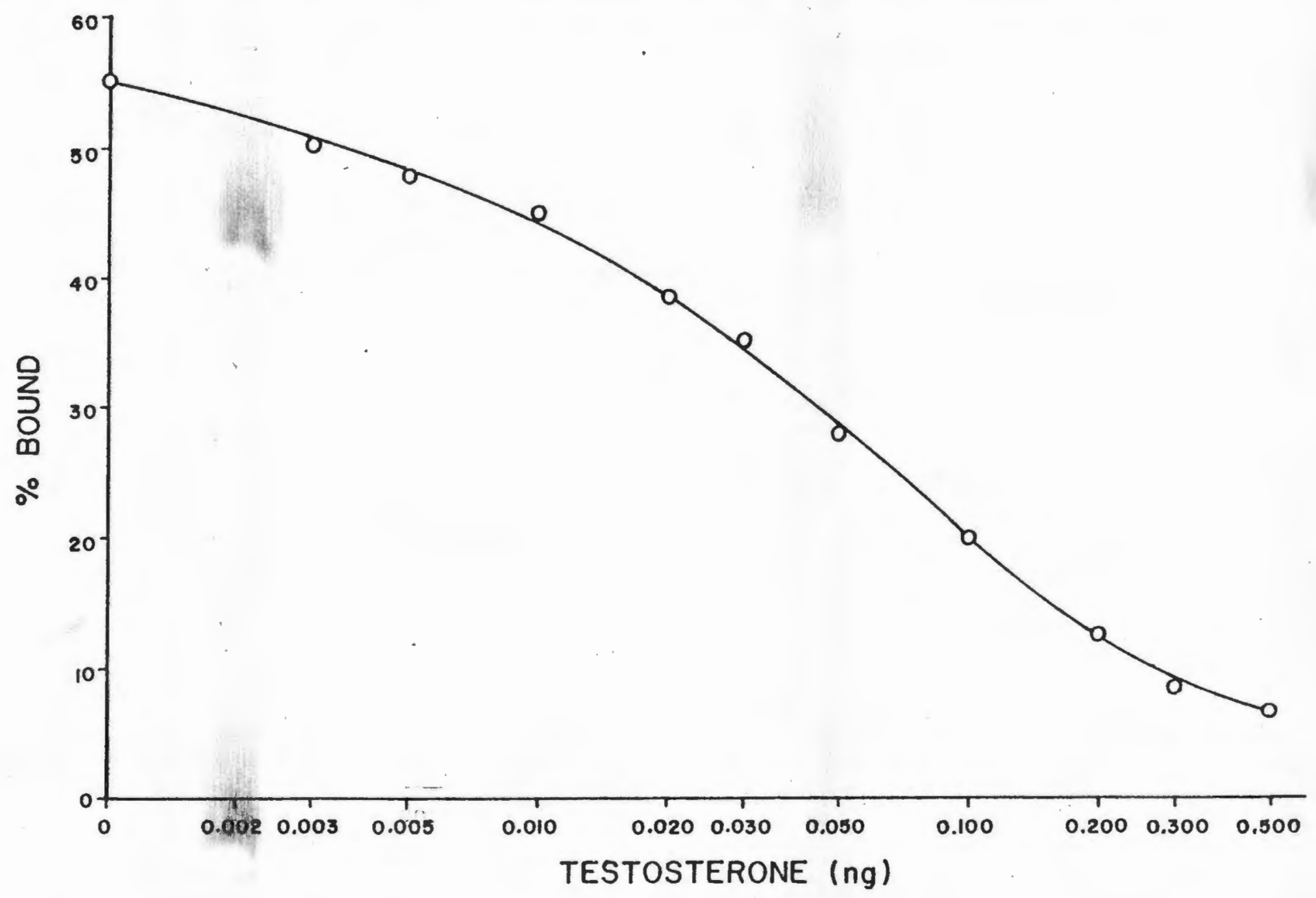


Fig. 9 Estradiol Standard Curve - 60 Day Open Study and 2 Day Single-Blind Study

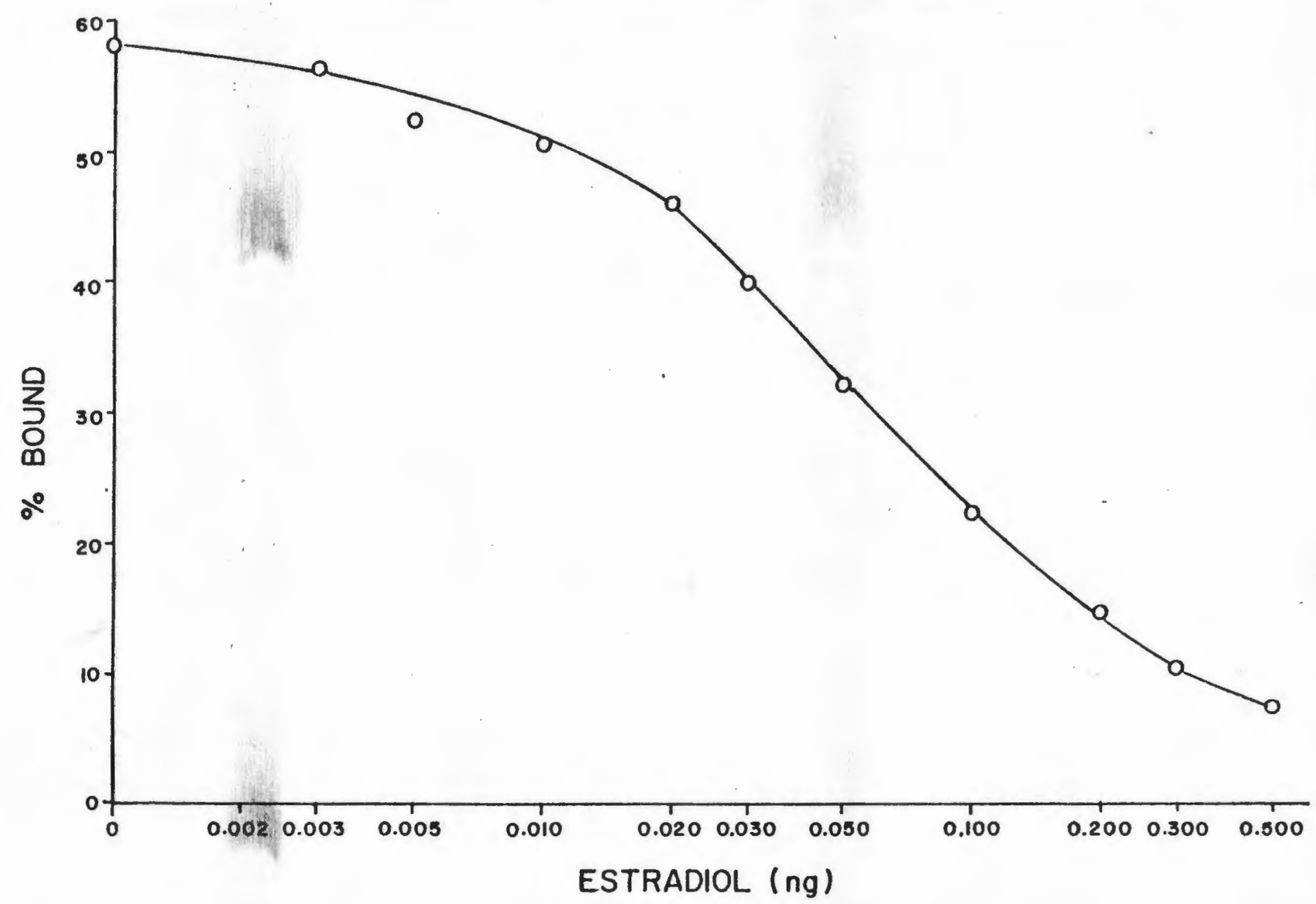


- Fig. 10 Testosterone Standard Curve - 30 Day Single-Blind Study

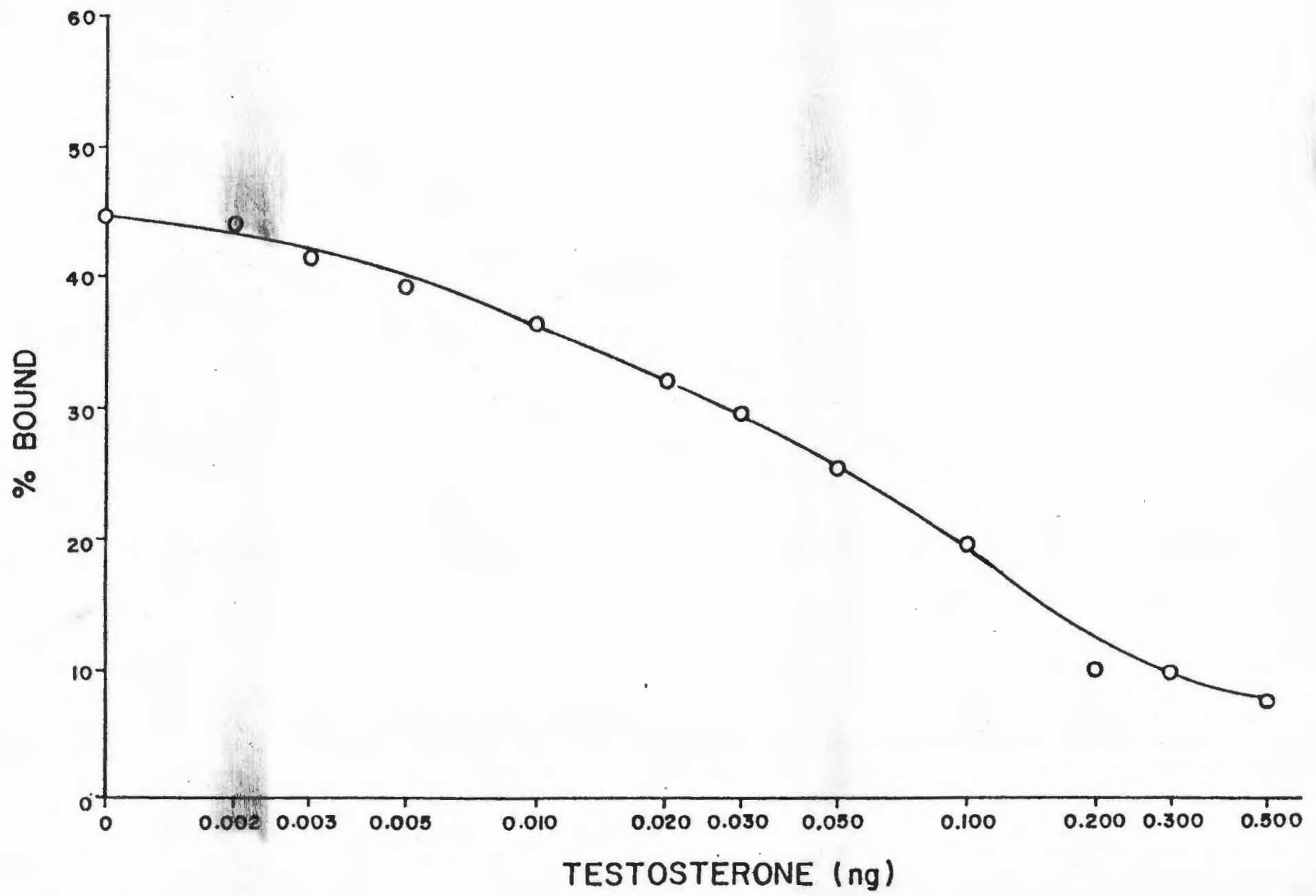


Fig. Il Estradiol Standard Curve - 30 Day Single-Blind Study

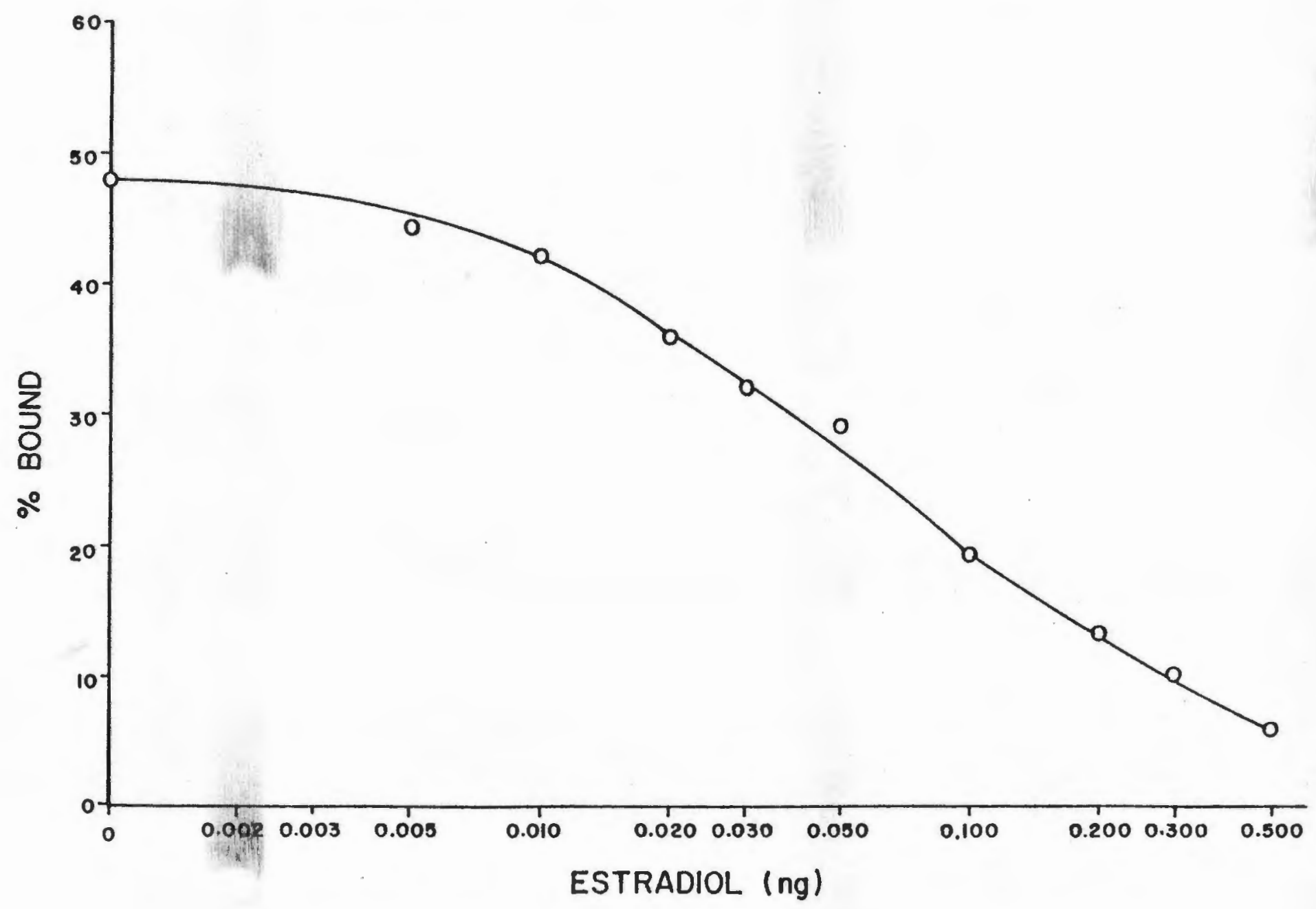


Fig. 12 Testosterone Standard Curve - 60 Day Single-Blind Study

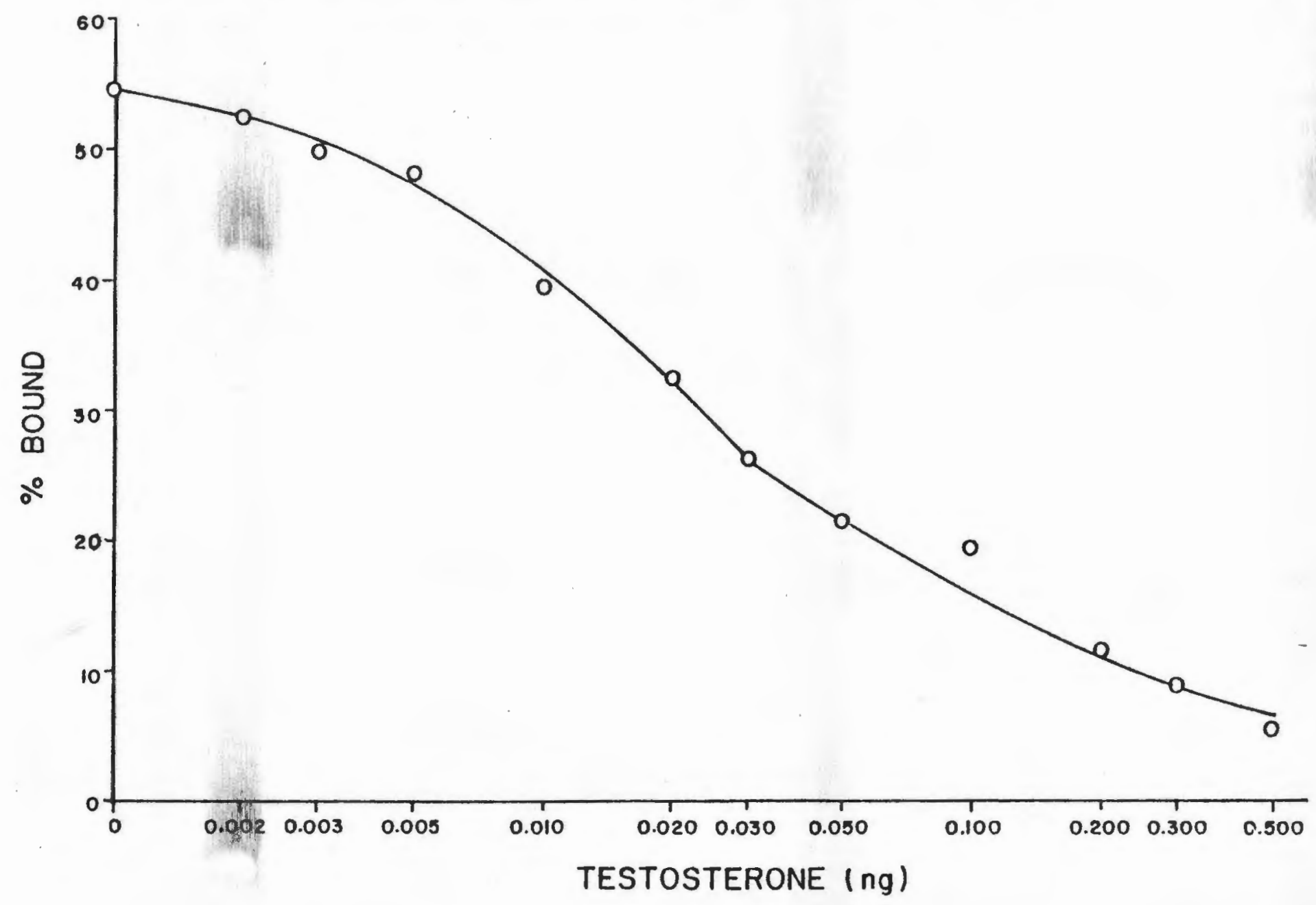


Fig. 13 Estradiol Standard Curve - 60 Day Single-Blind Study

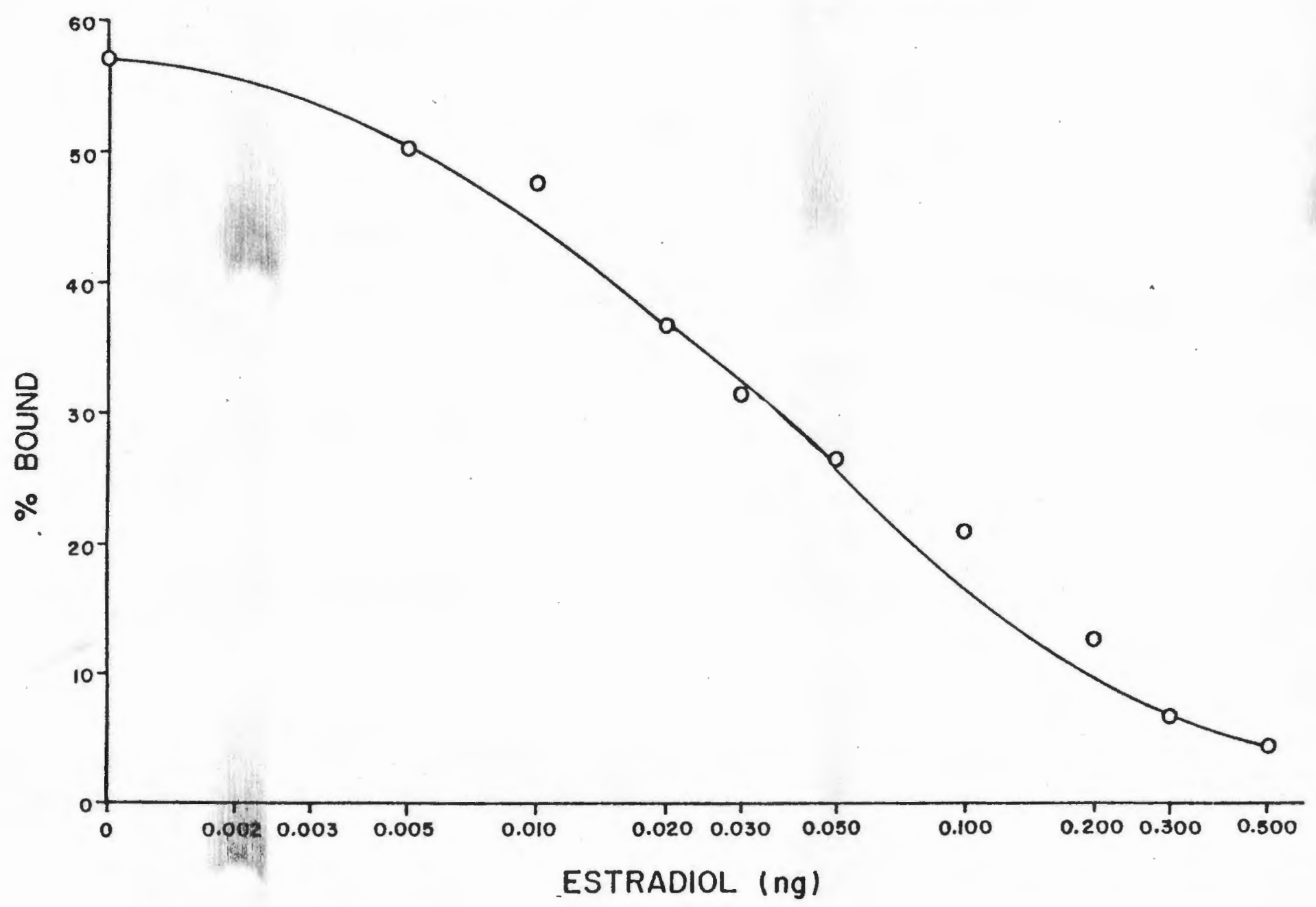


the amount of $\mathrm{T}$ or $\mathrm{E}$ in the original bloodstained sample by taking into account: 1 . the relative amount of bloodstained material extracted, 2. the functional recovery of the sample, 3. the reconstituted volume of the extract, and 4. the amount of that volume used in the assay (Eq. III). These adjusted values were put into ratio form (T:E) for the same sample at each age. The resulting ratios for all samples at each age group are shown in Tables 8 and 9 from the open and single-blind studies, respectively.

The $\mathrm{T}: \mathrm{E}$ ratios from the single-blind study were used to determine the accuracy of this method to predict the sexual origin of the bloodstained samples in this study at each age level. Since it was known that the numbers of male and female donors for this study were equal (eight), the ratios were independently divided into two equal groups at each age level. The higher values were designated as male and the lower values as female. These designations were then compared with the correct sexual origin of each sample. It was found that the selections correctly designated within the 30 and 60 day age levels werestat, $62.5 \%$ and $50 \%$ correct, respectively. A test for significance of a proportion was used to determine which of the percentages were significantly different from an expected $50 \%$ correct, since this was a single-blind study. The percent correct at the 2 day age level was the only value shown to be significant $\left(z=2\right.$, critical $\left.z_{.05}= \pm 1.96\right)$ within a $95 \%$ confidence level. 
Table 8

\section{T:E Ratios for Open Study \\ Age of Bloodstains (days)}

\begin{tabular}{crrrr} 
Sample \# & 2 & 30 & 60 & Sex \\
\hline 1 & 34.76 & 16.14 & 0.088 & $\mathrm{M}$ \\
2 & 32.67 & 12.35 & 0.159 & $\mathrm{M}$ \\
3 & 32.40 & 12.31 & 0.224 & $\mathrm{M}$ \\
4 & 38.71 & 1.94 & 0.042 & $\mathrm{M}$ \\
5 & 41.80 & 11.94 & 0.054 & $\mathrm{M}$ \\
6 & 79.25 & 11.53 & 0.062 & $\mathrm{M}$ \\
7 & 57.08 & 12.25 & 0.190 & $\mathrm{M}$ \\
8 & 41.69 & 3.41 & 0.136 & $\mathrm{M}$ \\
9 & 62.45 & 6.17 & 0.281 & $\mathrm{M}$ \\
10 & 49.67 & 9.23 & 0.364 & $\mathrm{M}$ \\
11 & 27.90 & 6.15 & 0.209 & $\mathrm{~F}$ \\
12 & 41.70 & 5.06 & 0.233 & $\mathrm{~F}$ \\
13 & 3.03 & 1.05 & 0.450 & $\mathrm{~F}$ \\
14 & 3.80 & 0.90 & 0.419 & $\mathrm{~F}$ \\
15 & 1.61 & 1.95 & 0.545 & $\mathrm{~F}$ \\
16 & 1.77 & 1.00 & 0.307 & $\mathrm{~F}$ \\
17 & 3.07 & 0.43 & 0.144 & $\mathrm{~F}$ \\
18 & 0.50 & 0.58 & 1.183 & $\mathrm{~F}$ \\
19 & 0.36 & 0.26 & 0.374 & $\mathrm{~F}$ \\
20 & 1.10 & 0.32 & 0.918 & $\mathrm{~F}$ \\
21 & $0.00 *$ & 0.89 & 1.567 & $\mathrm{~F}$ \\
22 & $0.00 *$ & 1.16 & 0.795 & $\mathrm{~T}$
\end{tabular}

* Testosterone nollet detected in these samples. 
Table 9

$\mathrm{T}: \mathrm{E}$ Ratios for Single-Blind study

Age of Bloodstains (days)

\begin{tabular}{ccccc} 
Sample\# & 2 & 30 & 60 & Sex \\
\hline 1 & 1.95 & 0.18 & 0.12 & $\mathrm{~F}$ \\
2 & 2.14 & 3.94 & 0.09 & $\mathrm{M}$ \\
3 & 2.23 & 3.32 & 0.12 & $\mathrm{M}$ \\
4 & 2.33 & 0.67 & 0.03 & $\mathrm{M}$ \\
5 & 4.37 & 0.49 & 0.20 & $\mathrm{M}$ \\
6 & 2.29 & 1.24 & 0.07 & $\mathrm{M}$ \\
7 & 2.79 & 0.85 & 0.15 & $\mathrm{M}$ \\
8 & 3.04 & 0.45 & 0.16 & $\mathrm{~F}$ \\
9 & 2.45 & 0.51 & 0.09 & $\mathrm{~F}$ \\
10 & 2.69 & 0.34 & 0.11 & $\mathrm{~F}$ \\
11 & 1.40 & 0.62 & 0.15 & $\mathrm{~F}$ \\
12 & 1.47 & 0.38 & 0.20 & $\mathrm{~F}$ \\
13 & 0.60 & 0.71 & 0.18 & $\mathrm{M}$ \\
14 & 1.50 & $0.00 *$ & 0.57 & $\mathrm{M}$ \\
15 & 3.22 & 2.19 & 0.67 & \\
16 & 2.67 & 1.88 & 0.09 & \\
\hline
\end{tabular}

* Testosterone modetected in this sample. 
Further statistical analysis of the T:E ratios for both the open and single-blind studies included T-tests for differences between male and female samples at each age level and between each age level within each sex. The results of each T-test are displayed in Tables 12 and 13 (Appendix B). Analysis of variance (ANOVA), based on a two-way mixed design, was also performed on the mean T:E ratios (Table 10) from each study. The ANOVA analysis should demonstrate: 1. whether there was a significant difference between male and female ratios, (conditions), 2. whether there was a significant difference between ratios for the same samples at different age levels (trials) and 3. whether there was a significant interaction between the age of the sample and the distinction between male and female samples (trials $x$ conditions). The source tables for each ANOVA are contained in Appendix C (Tables 14 and 15).

The T-test analysis for differences between males and females showed that there was no significant difference between male and female ratios only at the 60 day age level in the single-blig tudy at a $95 \%$ confidence levely the T-test analysis for differences between age levels several comparisons showed no significant difference at a $95 \%$ confidence level. In the open study there was no significant difference between all age comparisons for female ratios. In the blind study no significant difference was seen between the 2 and 30 day age levels for male ratios or between the 30 and 60 day levels for the female ratios. 
Table 10

Mean T:E Ratio Values and Standard Errors

Open study

Age (Days)
2
30
60

Males

Females

$$
\begin{aligned}
& 45.01 \pm 4.29 \\
& 9.04 \pm 1.34 \\
& 0.17 \pm 0.029
\end{aligned}
$$

$1.42 \pm 0.52$

$0.89+0.14$

$0.63 \pm 0.12$

$\begin{array}{rr} & \text { Single-Blind study } \\ 2 & 2.85 \pm 0.26 \\ 30 & 1.72 \pm 0.48 \\ 60 & 0.19 \pm 0.07\end{array}$

$1.79 \pm 0.24$

$0.50 \pm 0.13$

$0.19 \pm 0.06$ 
ANOVA of the mean $\mathrm{T}: \mathrm{E}$ ratios from the open study showed significant differences $(p=0.05)$ between males and females at each age level and also between the same samples at different age levels. There was also a significant interaction between these two factors. For the single-blind study, ANOVA showed significant differences $(p=0.05)$ between males and females at each level and also between the same samples at different age levels; however, no significant interaction occurred between these two factors.

The results from the cross-reactivity study were handled in a slightly different manner than the results from the other two studies. Instead of comparing the cpms of the standard and synthetic steroid samples to the total counts, they were compared to the zero standard counts to indirectly determine the percent of displacement of labeled antigen from the antiserum (Eq. II). The percentages obtained for each standard and synthetic steroid were then plotted against the corresponding log-dose of the steroid added (ng) on semi-logarithmic paper. The curves obtained in the testosterone cross-re livity for testosterone, ethinyl,estradiol, norethindrone and norgestrel are displayed in Figure 14. The curves obtained in the estradiol cross-reactivity study for estradiol, ethinyl estradiol, mestranol, norethindrone, norethynodre1, norgestrel and ethynodiol diacetate are displayed in Figure 15.

The percent of cross-reactivity any compound shows with an antiserum is determined at 50 용 displacement of the 
Fig. 14 Testosterone Antisenm Crossreactivity Curves

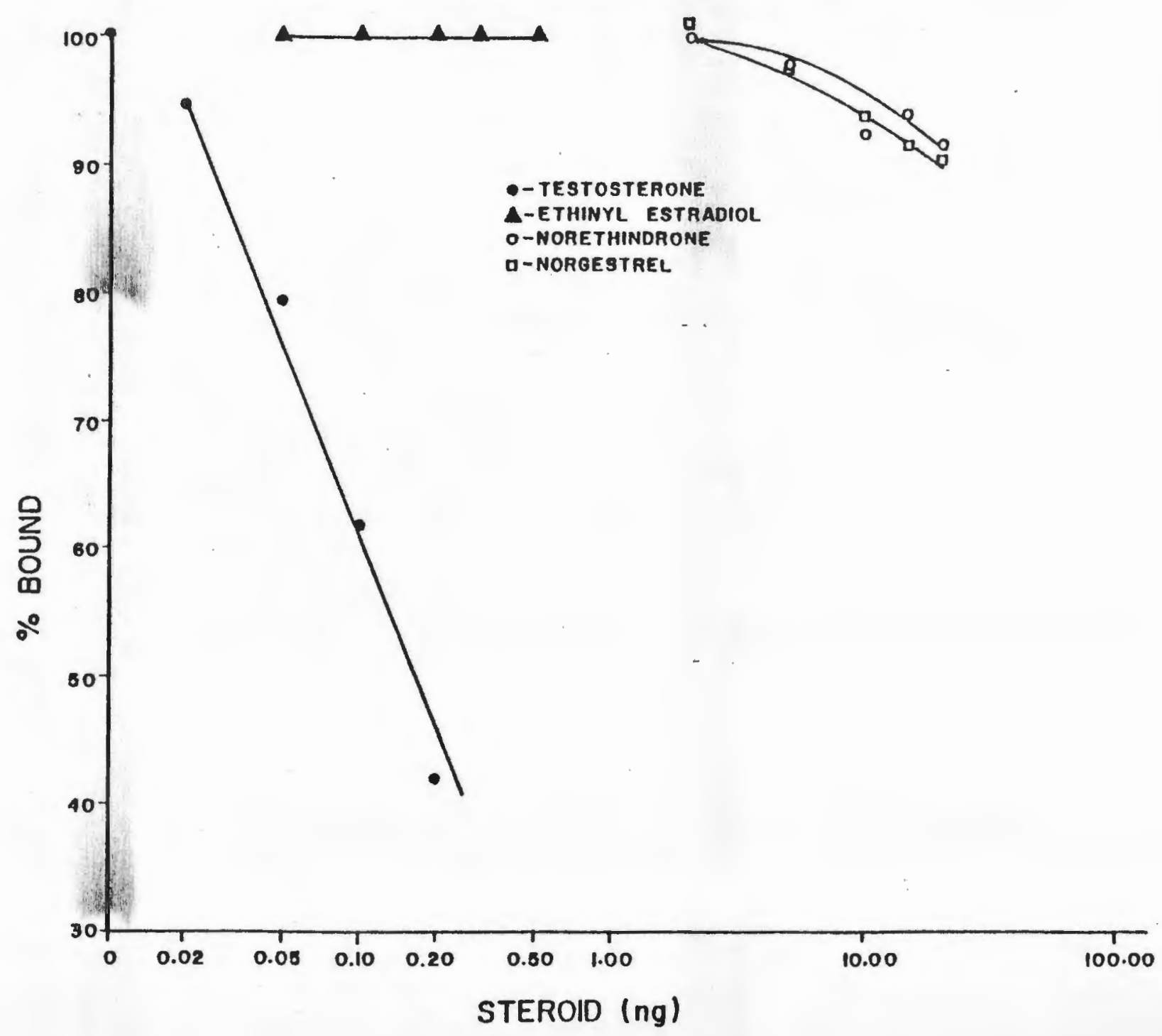


Fig. 15 Estradiol Antiserum Crossreactivity Curves

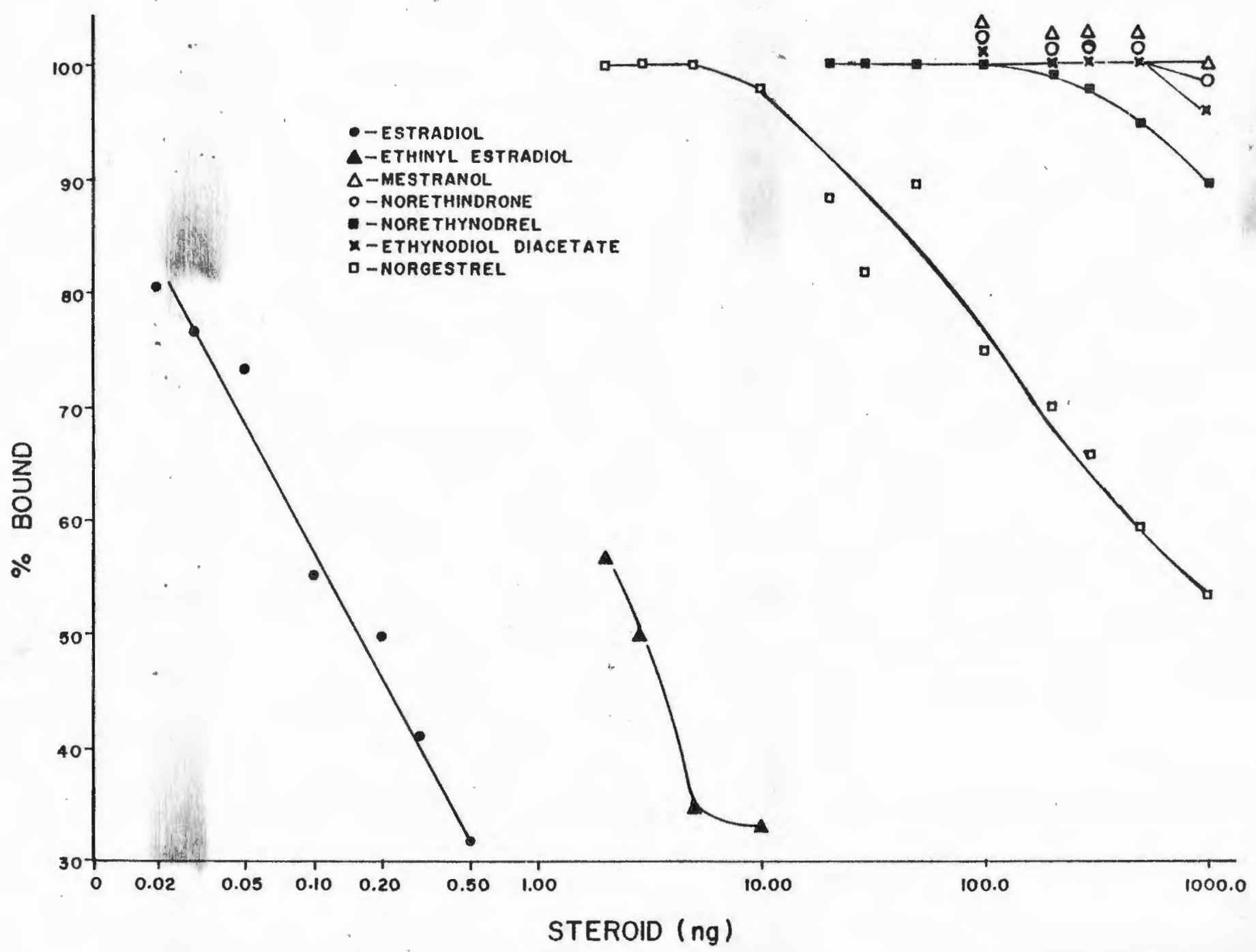


labeled antigen. The amount of the target antigen needed to displace 50 \% of the labeled antigen is divided by the amount of the compound in question needed to displace the same amount of labeled antigen. This value is then multiplied by 100 to obtain the percent cross-reactivity at $50 \%$ displacement.

Only one of the synthetic steroids tested showed $50 \%$ displacement at the concentrations tested (Table 11). Ethinyl estradiol showed a $5.00 \%$ cross-reactivity with the estradiol antiserum. The other compounds tested showed less than $0.01 \%$ cross-reactivity with either the testosterone or estradiol antisera. 
Table 11

\section{Cross-Reactivity of steroids \\ Percent Cross-Reactivity at 50\% Displacement}

Compound

Testosterone*

Dihydrotestosterone*

Estradiol-17 $\alpha$ *

Estrone*

Estradiol-17 $\beta$ *

Estriol*

Ethinyl Estradiol

Mestranol

Norgestre 1

Norethindrone

Norethynodrel

Ethynodiol Diacetate
T-Antiserum

100.00

56.00

0.10

0.05

0.05

0.05

NS **

$--$

NS * *

NS * *

$--$
E-Antiserum

0.001

100.00

50.00

25.00

5.00

5.00 NS * * NS * * NS ** NS** NS * *

ॠValues for these compounds were taken from the Protocols supplied with RIA kits.

** NS - Not significant at the therapeutic level or at higher levels tred (less than $0.01 \%$ cross-reactirity). 


\section{DISCUSSION}

The basic principle underlying this study is the wellestablished endocrinological differences between males and females in terms of the levels of two particular steroid hormones--testosterone and estrogen. Besides the basic difference in the levels of these hormones between the sexes, the levels are affected by age, physical condition and by certain drugs.

Testosterone is formed in the interstitial cells of the Leydig region in the male testes. In females testosterone is produced as an intermediate in estrogen synthesis and in the reduction of androstenedione and adrenal corticosteroid. It is normally secreted by the female ovaries in minute amounts. Levels of testosterone are relatively low in male children and in most females. Testosterone appears in significant quantities in newborn males and in adult males any time after pubertw. These levels begin to dwindle in males after age 40 , and decrease to about one-fifth the pak level by age 80 .

In normal nonpregnant females estrogens are cyclically secreted by the ovaries, with minute amounts secreted by the adrenal cortices. During pregnancy tremendous quantities are also secreted by the placenta, up to fifty times that secreted by the ovaries during a normal cycle. In males, 
estrogens are present at about one-fifth the level found in nonpregnant females. Estrogen in males is produced during the reduction of testosterone and may also be produced in the seminiferous tubules and interstitial cells. Levels of estrogens are relatively low in female children and they begin to rise and fall in a cyclic pattern after puberty. Estrogen levels begin to taper off at menopause (age 40-50) and approach zero after menopause.

The experiments in this study were designed to determine the limitations involved in applying the RIA technique in the forensic sciences for the purpose of identifying the sexual origin of a bloodstain utilizing the hormone principle. The experiments were devised to test several aspects of this application. Both the open and single-blind experiments tested the capability of commercially available RIA kits to quantitate testosterone and estrogen in extracts of prepared bloodstains and determined whether the age of a bloodstain affects that quantification. The single-blind study also allowed a determination to be made on the accuracy of using ther:E ratio as a basis for discriminating between male and female bloodstains. The cross-redetivity study became an essential part of this study because of the possible presence of synthetic steroids in bloodstains from a source such as oral contraceptives. This experiment provided an indication of the possible interference these steroids might cause by reacting significantly with the antiserum used in the RIA techniques. 
The recovery results from each assay showed that steroids are easily recovered from bloodstains when extracted with diethylether. The average recovery for both testosterone and estrogen was about $70 \%$ or better (Table 7). In three assays the recoveries were less than 50\%. In the testosterone assay of the 2 day open study the recovery was only $46.5 \%$. This extraction was performed using methylene chloride. Both testosterone and estrogen assays of the 30 day single-blind study showed less than $30 \%$ recovery for unknown reasons. In the clinical use of these RIA kits, recoveries of less than $40 \%$ are considered too low and should be repeated; however, in this study this was not possible and the assays were carried out as usual.

Radioimmunoassays of the sample extracts produced data which indicated that significant amounts of each steroid are detectable. These amounts were adjusted accordingly and put into ratio form, $T: E$ (Tables 8 and 9), for comparisons. The adjusted levels detected for the samples showed that testosterone levels were within the ranges reported for males and les in all but the 60 day studysfoth experiments where testosterone levels were well below those ranges. Estrogen levels were above reported ranges in all assays on male samples and in three of the six assays on female samples. This may be due to a higher degree of cross-reactivity (total estrogen) in the estrogen RIA than in the testosterone RIA. 
Comparisons were made within each experiment using the ratios to determine whether there was a significant difference between male and female ratios and if there was a significant difference between bloodstains at different age levels (2, 30 and 60 days), which were prepared from the same blood source. Analysis of variance, two-way mixed design, demonstrated that: 1. there was a significant

(p 0.05) difference between male and female ratios, 2 . the age of a bloodstain influences the amount of steroids detected, and 3. in the open study experiments the age of the bloodstain affected the ability to distinguish between male and female ratios. This interaction of the two major factors of sex and bloodstain age was not seen in the singleblind study which may be due to another time factor: the age of the RIA kits.

T-tests were conducted to determine whether any individual comparisons were not significantly different as indicated by ANOVA. In male vs. female comparisons only the 60 day single-blind study was not significant, which again may be due to age of the RIA kits. For compareing of samples from the same blood source at different bloodstain age levels there were five comparisons which were not significant. There was very little consistency between the open and single-blind studies in terms of the significance or nonsignificance of a particular comparison. However, it was observed that values for female bloodstains showed less 
variations between the three age levels $(2,30$ and 60 days) tested than that seen for the male bloodstain values.

From the ratios obtained in the single-blind study determinations were made at each age level on the accuracy of predicting the sex of a particular sample. The accuracy decreased as the age of the bloodstain increased with only the $75 \%$ accuracy at the 2 day level being significant. This accuracy may also be affected by the age of the RIA kit. Clinically the RIA kits have a useful life of $3-4$ months. The time involved in completing all assays in this study required approximately 6 months. Therefore, the assays in the single-blind study were accomplished during the outer limits of the RIA kits' clinical life. This could explain the dramatic differences seen between ratios from the two experiments. In the open study the ratios at the 2-day level are much higher than those from the 2 day singleblind study. However, the ratios from the 2 day singleblind study were between those from the 30 and 60 day open study ratios. A supporting fact for this time factor may be seen in the standard curves prepared for each assay. An indication of deterioration is a shift in the standatat curve to the right. This shift is seen to a slight extent when comparing the standard curves (Figs. 4-13). Another factor which would affect these values was the dilution of the antiserum. For most cases the dilution should produce between 40-50\% binding but, this was not the case in all assays. 
In immunoassays the rule is that the more dilute the antiserum the more sensitive the assay. Therefore, when the dilution produced greater than $50 \%$ binding the assay was less sensitive than if the dilution showed $40 \%$ binding. The cross-reactivity experiment showed that there is very little direct interference from synthetic steroids. only ethynyl estradiol showed any significant crossreactivity with the estradiol antiserum. However, these steroids may have significant indirect effects, since they have been shown to decrease the total endogenous estrogen while they cause slight increases in testosterone. This becomes important in women who are taking oral contraceptive preparations. In the open study care was taken to take blood samples from women who were not taking these preparations. However, in the single-blind study the female donors were not selected on this basis and it was not known whether or not any of these subjects were taking such medication. This may also have affected the female ratios to some extent, in the single-blind study. If the estrogen levels are decreased fe testosterone levels are incres a female sample may have been identified as male due to an elevated $\mathrm{T}: \mathrm{E}$ ratio.

A study of this kind attempts to open a new line of identification to the forensic serologist. Although there are several markers which are readily identified there is a great need for detection of other markers which further 
identify the individual from whom a bloodstain originated. With the development of specific antisera the identification of several genetic markers is easily accomplished. This principle can also be applied to physiological factors which vary as a result of genetic programming. To this end this initial investigation was devised to apply such techniques, through RIA methodology, for determining the sexual origin of a bloodstain based on the amounts of testosterone and estrogens detected.

The limitations of this particular study lie in the time factors involved. The effects of age in terms of the age of the bloodstain, the age of the person from whom the blood sample was obtained and the age of the RIA kits utilized, have been discussed. The first two are beyond the control of the investigator and the third must be carefully monitored in order to have consistence between investigations. It is recommended that future studies utilize larger numbers of subjects as blood sources and that the subjects be screened as to whether they are taking specific medication, sutis oral contraceptives which may cerfere with the RIAs. In this way a true indication could be made as to the accuracy of this method in both the presence and absence of interfering substances. It is hoped that this study will contribute to making this procedure as common in the forensic laboratory as are the procedures for identifying the components of the $A B O$ system. 


\section{SUMMARY AND CONCLUSIONS}

An investigation was made concerning the ability of commercially available RIA kits to quantify testosterone and estrogens in extracts of dried bloodstains, for the purpose of determining the sexual origin of those bloodstains. Whole blood obtained from male and female volunteers, was used to prepare twelve bloodstains on pieces of $2 \times 2 \mathrm{~cm}$ white cotton linen, for each blood sample. Bloodstains were extracted and RIA carried out on the extracts at 2 , 30 and 60 days after their initial preparation. Resulting values for testosterone and estrogen from each extract were put into $T: E$ ratios. Ratios were compared for male vs. female differences and also for differences between samples from the same blood source at the three $(2,30$ and 60 days) age levels. The accuracy for discriminating between bloodstains from male and female sources and the direct interference of several synthetic steroids were also determined for this appliterion of the RIA technique.

A significant difference was seen between ratios from male and female sources in five of the six comparisons. Only the final comparison, 60 day single-blind assay, showed no significant difference between male and female bloodstains. There was also a significant difference between ratios for bloodstains from the same source at the different 
time intervals $(2,30$ and 60 days). Time was also significant in terms of the age of the RIA kits, since there was an obvious difference between ratios determined for the bloodstains in the open and single-blind studies. The accuracy of this method was shown to be $70 \%$ or less in the single-blind study. Direct interference from the synthetic steroids was minimal with only one compound, ethynyl estradiol, showing any significant cross-reactivity (5\%) with the estradiol antiserum.

The RIA method then is a potentially useful tool with applications in the forensic sciences. For the purpose of sexual identification the RIA techniques needed are readily available from commercial sources. From this study it has been demonstrated that: 1. the RIA kits are capable of quantifying the amounts of testosterone and estrogen present in extracts of bloodstains, 2 . the $\mathrm{T}: \mathrm{E}$ ratio serves as a fairly accurate basis for discriminating between male and female samples, and 3 . the synthetic steroids tested have no direct significant effect on the RIA results. It was also shown that is procedure is subject to several limitations, the major one being time in terms of the age bloodstain, and the age of the RIA kit. A financial limitation arises out of the need to use fresh kits for sensitivity and accuracy in this method, since sensitivity decreases as the age of a RIA kit increases.

Also one must consider the indirect effects of the synthetic steroids on the RIA results, since endogenous levels 
of estrogen and testosterone are affected. This may also have influenced the accuracy determinations from the singleblind study. Finally, a double-blind study in which medical information is available might produce more significant data. Further investigation of these factors is therefore warranted. 
APPENDIX A

Equations

I Fractional Recovery (FR):

$\mathrm{FR}=\frac{\text { Net } \mathrm{cpm} \text { for sample } \mathrm{x} 4 \text { * }}{\text { Average net cpm for total recovery standards }}$

II Percent Radioactivity Bound ( $\left.\begin{array}{l}q \\ \text { B }\end{array}\right)$ :

$\approx \mathrm{B}=\frac{\text { Corrected } \mathrm{cpm} \text { standard, sample or syntheticX100 }}{\text { Corrected total count } \star \star}$

II Steroid Concentrations of Samples:

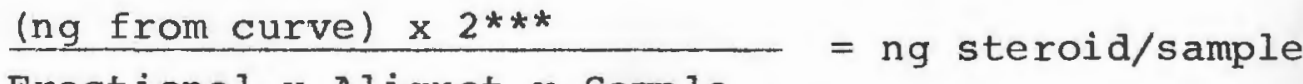

Fractional x Aliquot $x$ Sample

Recovery Assayed Extracted

$\mathrm{ml}$

* Since one-fourth of the reconstituted extract is counted.

* * Corrected zdro standard count was used for standard and synthetic steroid counts in the cross-reactivity study.

$\star * *$ Since the dried extract is reconstituted to $2.0 \mathrm{~m} 1$ with absolute ethanol. 


\section{APPENDIX B}

Table 12

T-Test Analysis for Sex

Sample Age (days)

\begin{tabular}{|c|c|c|c|c|c|}
\hline & 2 & 30 & 60 & $\mathrm{df}$ & Critical t.05 \\
\hline $\begin{array}{l}\text { Open study } \\
\text { Single-Blind }\end{array}$ & 10 & 6.04 & 3.83 & 22 & $2.074^{4}$ \\
\hline study & 3.03 & 2.46 & $0.31 *$ & 14 & 2.145 \\
\hline
\end{tabular}

*Not significant at the 0.05 level.

Table 13

T-Test Analysis for Age

Age Comparisons (days)

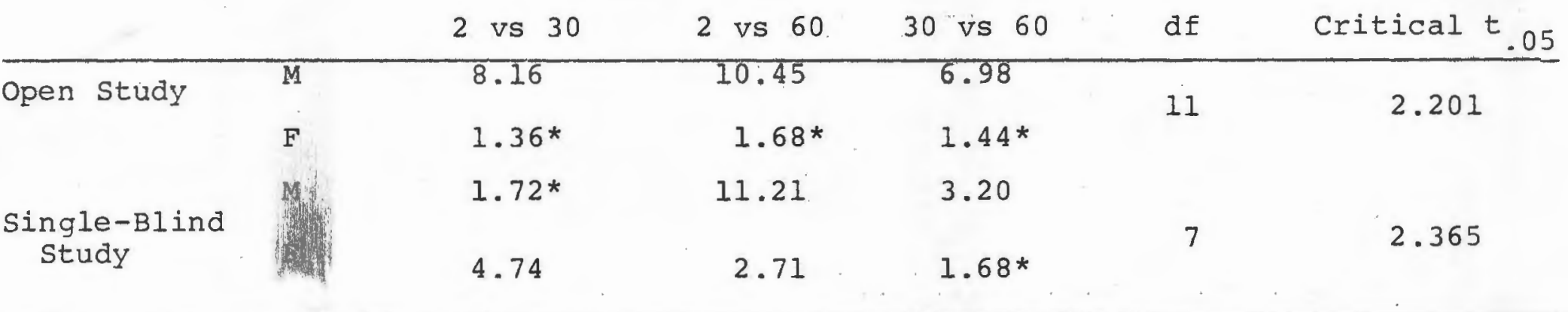

*Not significant at the 0.05 level. 
APPENDIX C

Table 14

Analysis of Variance ${ }^{1}$ Source Table-Open Study

\begin{tabular}{lrrrrr}
\multicolumn{1}{c}{ Source } & \multicolumn{1}{c}{ SS } & df & \multicolumn{1}{c}{ MS } & F & $\mathrm{p}^{2}$ \\
\hline Total & 21452.16 & 71 & & & \\
Between Subjects & 6167.05 & 23 & & & \\
$\quad$ Conditions (M,F) & 5258.76 & 1 & 5258.76 & 127.36 & $\mathrm{~S}$ \\
$\quad$ Error & 908.29 & 22 & 41.29 & & \\
Within Subjects & 15289.11 & 48 & & & \\
$\quad$ Trials (2,30,60) & 6993.04 & 2 & 3496.52 & 18.57 & $\mathrm{~S}$ \\
$\quad$ Trials X Conds. & 6541.59 & 2 & 3270.80 & 17.37 & $\mathrm{~S}$ \\
Errors & 8283.68 & 44 & 188.27 & & \\
\hline
\end{tabular}

Table 15

Analysis of Variance ${ }^{1}$ Source Table-Single-Blind study

\begin{tabular}{lrrrrr} 
Source & SS & df & MS & F & $\mathrm{p}^{2}$ \\
\hline Total & 68.24 & 45 & & & \\
Between Subjects & 11.39 & 15 & & & \\
$\quad$ Conditions (M,F) & 6.95 & 1 & 6.95 & 21.92 & $\mathrm{~S}$ \\
Error & 4.44 & 14 & 0.32 & & \\
Within Subjects & 56.85 & 30 & & & \\
Trials (2,30,60) & 36.64 & 2 & 18.32 & 28.54 & $\mathrm{~S}$ \\
Trials X Conds. & 3.52 & 2 & 1.79 & 2.79 & $\mathrm{NS}$ \\
Error & 16.69 & 26 & 0.64 & & \\
\end{tabular}

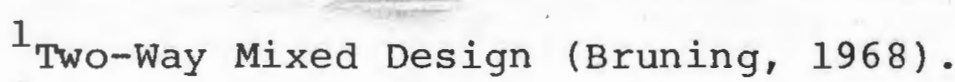

${ }^{2}$ s-Significant at the 0.05 leve 1 .

NS-Not significant at the 0.05 level. 
REFERENCES

Abraham, G.E.: Radioimmunoassay of Steroids in Biological Materials IN Radioimmunoassay and Related procedures in Medicine: Proceeding of a Symposium. Sept. 1973, Instanbul, International Atomic Energy Agency, Vienna, pp. 3-27, 1974.

Aragones, J. and Egozcue, J.: A method for sexing 90-Dayold Blood Stains in Absorbent and Non-Absorbent Materials, Acta Genet. Med. Gemellol, 22: 113-116, 1973.

Back, D.J., Breckenridge, A.M., Crawford, F.E., McIver, M., Orme, M., Park, B.K., Rowe, P.H. and Smith, E.: Kinetics of Norethindrone in Women. Clin. Pharmacol. Ther., 24: (4): 439-447, 1978 .

Bagshawe, K.D.: Tumor-Associated Antigens. British Med. Bul1., 30: (1): 68-73, 1974 .

Bangham, D. and Cotes, P.: Standardization and Standards. British Med. Bull., 30: (1): 12-17, 1974 .

Behring, E. and Kitasato, S.: Ueber das Zustandekommen der diphtherie-immunitat und der tetanus-immunitat bei thieren Deutsch Med. Wschr., 16: 113-114, 1890.

Bischoff, F. and Bryson, G.: Pharmacodynamics and Toxicology of Steroids. Adv. Lipid Res., 15: 61-157, 1977.

Bolt, H.M. and Bolt, W.H.: Pharmacokinetics of Mestranol in Man in Relation to Its Oestrogenic Activity. Europ. J. Clin. Pharmacol., 7: 295-305, 1974.

Brenner, P.F., Mishell, D.R., Stanczyk, F.Z. and Goebelsman, U.: Serum Levels of d-Norgestrel, Luteinizing Hormone, Estradiol and esterone in Women During and Foltaring Ingestion of cortolnation oral contraceptives Containg dl-Norgestrel. Amer. J. of Obstetrics and Gynecology, 129: (1): 133-140, 1977.

Briggs, M.: Biochemical Effects of Oral Contraceptives. Advances in Steroid Biochemistry and Pharmacology, $\underline{5}$ : $65-$ $160,1976$.

Brown, B.L. and McWright, C.G.: Sex Determination from Dried Bloodstains Utilizing Radioimmunoassay-A Preliminary Report IN American Academy of Forensic Sciences Book of Abstracts, $2 \overline{8 t h}$ annual meeting, p. 7, 1976 . 
Brown, B.L.: Sex Determination from Dried Bloodstains Utilizing Radioimmunoassay-Application to Forensic Samples, IN American Academy of Forensic Sciences Book of Abstracts, 29th annual meeting, p. 70, 1977.

Bruning, J.L. and Kintz, B.L.: Computational Handbook of Statistics, Scott, Foresman and Company, Glenview, III., 1968 .

Carpenter, P.: Immunology and Serology, W.B. Saunders Co., Philadelphia, pp. 28-47, 1975.

Castro, A., Shih, H. and Chung, A.: A Direct Plasma Testosterone Radioimmunoassay. Experimentia, 15: (11): 1447-48, 1973.

Castro, A., Shih, H. and Chung, A.: A Simple Radioimmunoassay of Plasma Testosterone Without Column Chromatography. Steroids, 23: (5): 625-638, 1974 .

Cerceo, E. and Elloso, C.: Rapid Method for the Estimation of Total Free Estrogens in Plasma. Anal. Chem., 46: (11): $1578-1580,1974$.

Challand, G., Goldie, D., and Landon, J.: Immunoassay in the Diagnostic Laboratory. British Med. Bull., 30: (1): $38-43$, 1974 .

Cook, C.E., Karim, A., Forth, J., Wall, M., Ranney, R. and Bressler, R.C.: Ethynodiol Diacetate Metabolites in Human Plasma. J. of Pharmacol. and Exper. Ther., 185: (3): 696$702,1973$.

Culliford, B.J.: The Examination and Typing of Bloodstains in the Crime Laboratory, National Institute of Law Enforcement and Criminal Justice PR 71-7, U.S. Government Printing Office, Washington, D.C., December, $1=71$.

D'Agata, R., Gulizia, S., Ando, S. and Magro, E.: Radioimmunoassay of tsma Estrogens. Boll. Soc. It. - Stet. Spor., 49: $524-528,1973$ :

Dawson, E., Denissen, A. and van Weemen, B.: A Simple and Efficient Method for Raising Steroid Antibodies in Rabbits. Steroids, 31: (3): 357-366, 1978 .

Ekins, R.P.: Basic Principles and Theory: Radioimmunoassay and Saturation Analysis. British Med. Bull., 30: (1) : 3-11, 1974 .

Forti, G., Pazzagli, M., Calabresi, E., Fiorelli, G. and Serio, M.: Radioimmunoassay of Plasma Testosterone. Clinical Endocrinology, 3: 5-17, 1974 . 
Garner, D.: Hemoglobin Identification in Forensic Serology, Current Laboratory Practice, p. 2, April, 1979.

Grunbaum, B.W. and Crim, M.: Some New Approaches to the Individualization of Fresh and Dried Bloodstains. J. Forensic Sciences, 21: (3): 488-497, 1976.

Guyton, A.C.: Textbook of Medical Physiology. W.B. Saunders Company, Phil., Pa., 5th ed., pp. 107z-1103, 1976.

Hafs, H., Niswender, G., Malven, P., Kaltenbach, C., Zimmerman, R. and Condon, R.: Guidelines for Hormone Radioimmunoassays. J. Animal Sciences, 46: (4) 927-928, 1977.

Horeisi, J. and Smetana, R.: The Isolation of Gamma Globulin from Blood-Serum by Rivanol. Acta Medica Scandinavica, 155: $65-70,1956$.

Hunter, W.: Preparation and Assessment of Radioactive Tracers. British Med. Bull., 30: (1): 18-23, 1974.

James, V. and Jeffcoate, S.: Steroids: Radioimmunoassay and Saturation Analysis. British Med. Bull., 30: (1): 5054,1974 .

Joyce, B.G., Fahmy, D., Hillier, S.G.: Specific Determination of Testosterone in Female Plasma by Radioimmunoassay. Clinica Chimica Acta, 62: 231-283, 1975.

Kubasik, N. and Sine, H.: Results for Serum and Plasma Compared in 15 selected Radioassays. Clin. Chem., 24: (1) : 137-9, 1978 .

Kushinsky, S., and Anderson, M.: Comparison of DextranCoated Charcoal and Ammonium Sulfate in the Radioimmunoassays of Estrogens. Steroids, 25: (1): 145-150, 1975.

Landsteiner, K.: Specificity of Serological Reactions. Harvard University Press, Cambridge, Mass., 1962.

Lieberman, S., Frlanger, B., Beiser, S. and Agate, tw : Steroid-Protein Conjugates: Their Chemical, Immunochemical and Endocrinological Properties. Progr. Hormone Res., 15: 165-200, 1959 .

Marks, V., Morris, B.A. and Teale, J.D.: Pharmacology: Radioimmunoassay and Saturation Analysis. British Med. Bull., 30: (1): 80-85, 1974 .

McArthur, J. and Colton, T.: Statistics in Endocrinology. Mass. Institute of Technology, pp. 325-392, 1970. 
Moller, M.R., Tausch, D., and Biro, G.: Radioimmunological Detection of Moxphine in Stains of Blood and Urine. $\mathrm{Z}$. Rechtsmedizin, 79: 103-107, 1977 .

Morrison, R.T. and Boyd, R.N.: Organic Chemistry, Allyn and Bacon, Boston, pp. 514-515, 1973 .

Murad, F. and Gilman, A.S.: Estrogens and Progestins IN The Pharmacological Basis of Therapeutics. 5th ed., L.S. Goodman and A.S. Gilman, editors, MacMillan Publishing Co., Inc., New York, pp. 1423-1450, 1975.

NEN : New England Nuclear Corp., Protocol: Estrogens $\left(E_{1} / E_{2}\right){ }^{3}$ H R.I.A. Pak, Cat. No. NEA-044, 1976.

NEN: New England Nuclear Corp., Protocol: Testosterone

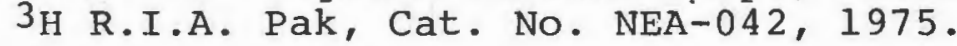

Nygren, K.G., Lindberg, P., Martinsson, K., Bosu, W.J.K. and Johansson, E.D.B.: Radioimmunoassay of Norethindrone: Peripheral Plasma Levels After Oral Administration to Humans and Rhesus Monkeys. Contraception, 9: (3): 265278,1974 .

Parker, C.: Radioimmunoassay of Biologically Active Compounds, Prentice-Hall, Inc., Englewood Cliffs, New Jersey, 1976.

Patterson, R. and Lurie, A.: A simple Assay Without Chromatography for the Clinical Laboratory. Amer. J. Clin. Path., $60: 879-884,1973$.

Peron, F.G. and Caldwell, B.V., editors: Immunologic Methods in Steroid Determination, Plenum Press, New York, 1970 .

Playfair, J., Hurn, B., and Schulster, D.: Production of Antibodies and Binding Reagents. British Med. Bull., 30: (1): 24-31, 1974

Porias, H., Carraño-Lopez, A., Sojo-Aranda, I., Gohn Martiacz, R., Cervantes, C., Parra, A. and Cortez-Gallegos, V.: Hormonal Content of Plasma and Endometrium of Women Taking Oral Contraceptives. Obstets. and Gynecol ., 52 (6): 703-707, 1978 .

Ranney, R.E.: Comparative Metabolism of 17-Alpha-Ethynyl Steroids Used in Oral Contraceptives. J. of Toxicology and Environmental Health, 3: 139-166, 1977.

Ratcliffe, J.: Separation Techniques in Saturation Analysis. British Med. Bull., 30: (1): 32-37, 1974. 
Roitt, I.: Essential Immunology. Blackwell Scientific Publications, oxfoxd, pp. 108-109, 1974.

Saferstein, R.: Forensic Serology IN Criminalistics: An Introduction to Forensic Science, Prentice-Hall, Inc., Englewood Cliffs, New Jersey, pp. 247-248, 1977.

Schehr, F.E.: The Sexual origin of Bloodstains: Specific Determination of Testosterone Using Radioimmunoassay, IN American Academy of Forensic Sciences Book of Abstracts, 29th annual meeting, p. 70, 1977.

Schwinger, Von E.: Geschlechtsbestimmung aus Blutspuren. Z. Rechtsmedizin, 70: 157, 1971.

Schwinger, Von E. und Troger, H.D.: Wie sicher ist die Gerchlechtsbestimmung in Blutspuren? Beitragege zur Gerichtlichen Medizin, 35: 267-71, 1977.

Sheldon, P.E. and Coppenger, C.J.: A Rapid Radioimmunoassay for Serum Testosterone. Steroids, 30: (2): 149-157, 1977.

Stahl, F.: Radioimmunoassay of Plasma Testosterone Without Chromatography. Endokrinologie, 65: (3): 288-292, 1975.

Stanczyk, F.z., Brenner, P.F., Mishell, D.R., Ortiz, A., Gentzschein, E.K. and Goebelsmann, U.: A Radioimmunoassay for Norethindrone (NET): Measurement of Serum Net Concentrations Following Ingestion of NET-Containing oral Contraceptive Steroids. Contraception, 18: (6): 615-633, 1978 .

Stuver, W.C., et al.: Sexing of Bloodstains, IN American

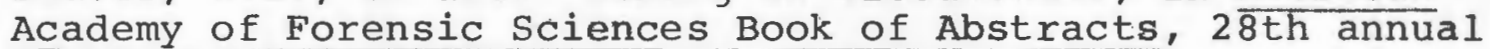
meeting, p. 7, 1976.

Sweet, G.H. and Elvins, J.W.: Studies by Crossed ElectroImmunodiffusion on the Individuality and Sexual Origin of Bloodstains. J. of Forensic Sciences, 21: (3): 498-509, 1976 .

Tateishi, K. Yamamoto, A., Ogihara, T. and Hayashith . : Enzyme Immunoassay of Serum Testosterone. Steroids, 30 : (1) : 25-32, 1977 .

Thorell, J.I. and Larson, S.M.: Radioimmunoassay and Related Techniques. The C.V. Mosby Company, Saint Louis, Mo., 1978 .

Verma, P., Curry, C., Crocker, C., Titus-Dillon, P. and Ahluwalla, B.: A Competitive Protein Binding. Radioassay for 17-Alpha-Ethynylestradiol in Plasma. Clinica Chemica Acta, 63: 363-368, 1975 . 
Vermeulen, A.: Determinations of Androgens in Plasma IN The Endocrine Eunction of the Human Testis Ed. by James, V.H.T. Vol. 1, Pp. 91-100, 1973.

Wigmore, R., Werrett, D., King; L., Whitehead, P. and Emes, A.: The Detection of $\mathrm{Y}$ Chromosomes in Bloodstains-A Reevaluation. J. of Forensic Sciences, 24: (2): 366-375, 1979.

Woodhead, J., Addison, G. and Hales, C.: The Immunoradiometric Assay and Related Techniques. British Med. Bull., 30: (1): 44-49, 1974 . 


\section{VITA}

Dennis Charles Hilliard was born to Mr. and Mrs. Daniel M. Hilliard on July 24, 1954 in New Haven, Connecticut. Mr. Hilliard obtained his elementary and secondary education in New Haven, Connecticut. In 1972, Mr. Hilliard enrolled at the University of New Hampshire and received a Bachelor of Science degree in Biochemistry in May, 1976. Mr. Hilliard began full-time graduate studies at the University of Rhode Island in September, 1976 where he completed the requirements for the Master of Science degree in Pharmacology and Toxicology in January, 1980.

Mr. Hilliard is married to the former Louise Frances Durso of New Haven, Connecticut. 